\title{
INFERÊNCIA PARAMÉTRICA E NÃO-PARAMÉTRICA EM ANALLISE DE SOBREVIVÊNCIA
}

\author{
LIGI ANA VAZ DE ARRUDA SILVEIRA CHALITA \\ Engenheira Agrônoma
}

Orientador: Prof. Dr. CASSIO R. DE MELO GODOI

Dissertacão apresentada à Escola Superior de Agricultura "Luiz de Queiroz", da Universidade de São Paulo, para obtenção do título de Mestre em Agronomia, Área de Concentracão: Estatística e Experimentação Agronômica.

$P I R A C I C A B A$

Estado de São Paulo - Brasil

Fevereiro - 1992 
Ficha catalográfica preparada pela Seção de Livros da Divisão de Biblioteca e Documentação - PCAP/USP

Chalita, Liciana Vaz de Arruda Silveira

C436i Inferência paramétrica e não-paramétrica em análise de sobrevivência. Piracicaba, 1992.

$96 \mathrm{p}$.

Diss.(Mestre) - ESALQ

Bibliografia.

1. Estatística agrícola 2. Inferência estatística I. Es cola Superior de Agricultura Luiz de Queiroz, Piracicaba

CDD $\quad 519.54$ 


\section{INFERENCIA PARAMÉTRICA E NÃO-PARAMETRICA EM ANÁLISE DE SOBREVIVENCIA}

LICIANA VAZ DE ARRUDA SILVEIRA CHALITA

Aprovada em: 24.02 .1992

Comissão Julgadora:

Prof. Dr. Cássio Roberto de Melo Godoi

ESALQ/USP

Prof. Dr. Jose Eduardo Corrente ESALG/USP

Profa Dra Sheila Zambello de Pinho IB/UNESP

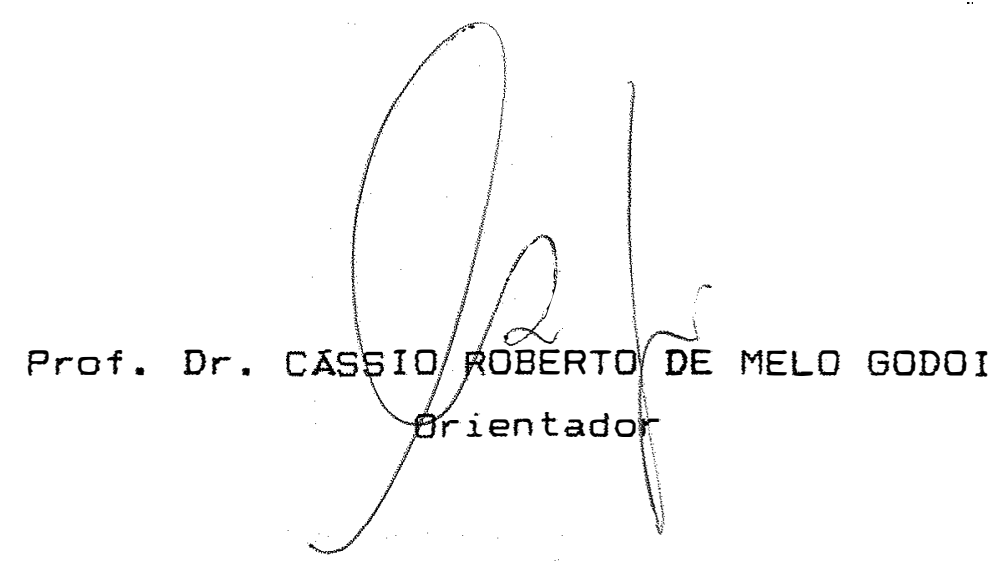


$i i$.

Aos meus pais, Ronaldo - Luiza, ao meu irmão, Ronaldo Luiz, ao meu esposo, Ronald, às minhas amigas, Dinara, Elvira e Lidia Raquel 
ii $i$.

$A G R A D E C O$

Ao Prof. Dr. Cássio Roberto de Melo Godoi pela contribui căo.

Ao Prof. Dr. José Eduardo Corrente pela orientaç̃o e pela grande amizade.

Aos professores do Departamento de Matemática - Estatística da ESALQ/USP pelos ensinamentos.

Ao Prof. Dr. Décio Barbin, à Profä Dra Clarice de Borges Demétrio a prof. Dr. Antonio Francisco I emma pela colaboracão e pela amizade.

Aos funcionários do Departamento de Matemática e Estatistica da ESALQUSP pelos servicos prestados.

Aos colegas do curso do mestrado, especialmente, Silvio Sandoval Zocchi, Dinara Xavier Fernandes e Elvira Barbosa de Freitas pelos momentos que passamos juntos.

Ao Departamento de Bicestatística da UNESP Botucatu pela col aboração.

A Beatriz Montrágio Costa pelo excelente trabal ho de datilografia.

A Teresinha de L. C. Aragon pela revisão de português.

As amigas Luciane Brajão, Lidia Raquel de Carvalho, Rosa Maria Alves, Marta Regina Munis, Dinara X. Fernandes e Elvira Barbosa de Freitas pelo apoio e pela ami zade.

À Deus por ter me dado muita fé e forcas para terminar este trabalho. 
SUMARIO

Păgina

1. INTRODUCÃO . . . . . . . . . . . .

2. REVISÃO DE LI TERATURA E CONCEITOS BÁSI COS. ........ 3

2. 1. Funçăo de sobrevi vênci a.............. 3

2.2. Funcão densidade de probabilidade (f.d.p. 2... 4

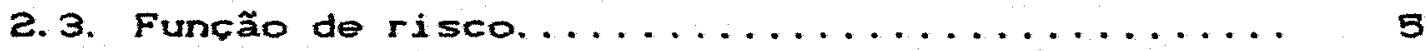

2. 4. Censura tipo $I \ldots \ldots \ldots \ldots \ldots \ldots \ldots$

2. 5. Censura tipo II................... 11

2. 6. Censura Aleatória.................. 12

2.7. Métodos não-paramétricos para estimacão das funçōes de sobrevi vência.............. 15

2.7.1. Método atuarial............... 15

2.7. E. Estimador Produto Limite de Kaplan-Meier.................... 19

2.8. Testes não-paramétricos para comparar duas f unçốes de sobrevi vência.............. 25 2.8.1. Teste de GEHAN (1965) (uma generalizacão do teste de Wilcoxon $\ldots \ldots \ldots \ldots \ldots$ as

2. 8. 2. Teste "Logrank".............. Z9

2.8. 3. Teste de Mantel Haenszel (1989)...... 30 . 
Página

2.9. Modelos paramétricos para estimacão de funçăo de sobrevi vência.................... 32

2.9.1. Modelo exponencial................ 38

2. 9. 2. Modelo de Weibull............. 46

2.10. Testes paramétricos para a comparação de duas distribuicones...................... 50

2.10.1. Comparacão de duas distribuicoñes exponenciais. .................

51

2.10.1.1. Teste da razăo de verossimi1 hanca.............. 5

2.10.1.2. Teste $F$ de Cox........ 53

2.10.2. Comparaç̃o de duas distribuicõos Heibull ...................

2.11. Eficiência assintótica relativa dos estimadores da funçăo de sobrevi vência..........

3. METODOLOGI A. ....................... 58

3.1. Métodos năo-paramétricos............... 59

3.2. Teste de "Logrank"..................

3. 3. Método paramétrico................. B1

3.4. Teste da razão de verossimilhança para diferenca entre duas amostras............ 83

3.5. Eficiência assintótica relativa........... 84

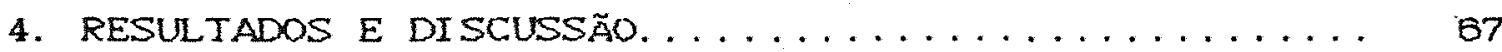


4.1. Método de Kaplan-Meier............... 70

4.2. Teste de "Logrank"................. 78

4. 3. Métodos paramétricos................. 80

4. 4. Teste de razâo de verossimilhança para duas $\operatorname{amostras} \ldots \ldots \ldots \ldots \ldots \ldots \ldots \ldots \ldots$

4.5. Eficiência assintótica relativa............ 86

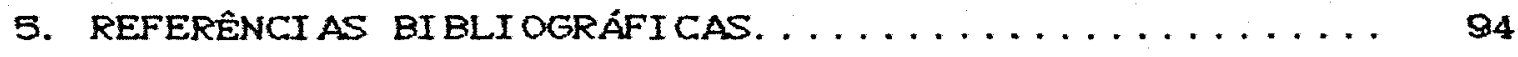


vii.

\section{INFERÊNCIA PARAMÉTRICA E NÃO-PARAMÉTRICA EM ANÁLISE DE SOBREVIVÊNCIA}

Autora: LICIANA VAZ DE ARRUDA SILVEIRA CHALITA Orientador: Prof. Dr. CÁSSIO R. DE MELO GODOI

\section{RESUMO}

Análise de sobrevivência consiste em um conjunto de técnicas paramétricas não-paramétricas que são aplicadas a variáveis positivas, tais como, tempo de falha de un componente físico, tempo de vida de unidades, etc.

As informaç̃os que se tem sobre esta variável

podem ser incompletas. Neste caso, diz-se que os dados são censurados seria interessante considerar essas observacões na análise.

- objetivo deste trabalho é fazer uma compilacão das técnicas mais utilizadas em análise de sobrevi vência considerando também dados incompletos com o intuito de aplicaçăo na área agronômica.

No entanto, na área agrária os experimentos ainda não são conduzidos para serem analisados como dadọs de sobrevivência. Acredita-se que seja por falta de informacão dos pesquisadores nesta linha. Devido a este fato. 
viii.

simulou-se dois conjuntos de dados com existência de censura com a finalidade de exemplificar a utilizacão dos métodos apresentados para a estimacão da funcão de sobrevi vência e testes paramétricos e não-paramétricos para verificacão da* diferenca de' duas populacôes. Calculou-se também a eficiência assintótica do modelo paramétrico em relacão ao não-par amétrico.

Concluiu-se que as técnicas de análise de sobrevivência se mostraram simples, apesar de seu desenval vimento teórico ser complicado, sendo perfeitamente viável sua aplicacão em dados de experimentos agronômicos ou florestais. 


\section{INFERENCE PARAMETRIC AND NONPARAMETRIC IN IN SURVIVAL ANALYSIS}

Author: LICIANA VAZ DE ARRUDA SILVEIRA CHALITA Adviser: Prof. Dr. CÁSSIO R. DE MELO GODOI

SUMMARY

Survival Analysis is a set of parametric or non parametric techniques applied on positive variables, such as failure of physical component, ilfe span of units.

The available information about this positive variable maybe incomplete. In this case, it is said that the data are censured and would be interesting to consider these observation in the analysis.

The objective of this dissertation is to make a compilation of the more used techniques in survival analysis dealing with incompleted data with the purpose of aplication in agronomic area.

However the experiments in agriculture aren't conducted like survival data analysis yet, because of the lack of information in this area. Thus two sets data were 
simulated with randon censured to exemplify the utilization the methods showed in the estimation of survival function, parametric and nonparametric tests for the verification of difference on two populations, also calculating the assimptotic relative efficiency of the parametric model in relation to the nonparametric model.

One conclude that, the survival analysis techniques are simple in spite of the complicated theoretical development, and his application is perfectly practicable in agriculture and foresty experiments. 


\section{INTRODUC̣ÃO}

A análise de sobrevi vência é um conjunto de técnicas e modelos estatisticos usados na análise do comportamento de variáveis aleatórias positivas, tais como, tempo de falha de alguns componentes físicos, tempo de sobrevivência até a morte de unidades sujeitas a un determinado tratamento, tempo de sobrevida de al guma especie florestal, tempo de sobrevi vência de insetos sujeitos a uma determinada dose de inseticida, etc.

Em muitas áreas de aplicação dessas técnicas estatisticas, por exemplo, em medicina ou engenharia, os pesquisadores usualmente estão interessados em analisar dados relacionados aos tempos de vida de unidades. Estes dados são usualmente conhecidos como dados de sobrevi vência e, em geral, as obser vações são incompletas.

No caso da observacão não conter a informação completa durante o tempo do estudo, diz-se que essa observação é censurada.

Na análise de sobrevi vência pode-se utilizar tanto técricas paramétricas como não-paramétricas para estimação da funcão de sobrevivência. As técnicas não. 
paramétricas devem preceder as técnicas paramétricas nos casos em que é possivel ajustar um modelo paramétrico aos dados. Quando há dificuldado na identificacão de um modelo paramétrico para as dados em estudo devem-se utilizar apenas técnicas năo paramétricas.

Assim, o objetivo deste trabalho é apresentar as técnicas paramétricas e não-paramétricas da Análise de Sobrevi vência aplicáveis a experimentos da área agronômica florestal, mostrando a eficiência do método paramétrico em rel ação ao não-paramétrico. 


\title{
2. REVISÃO DE LITERATURA E CONCEITOS BÁSICOS
}

\begin{abstract}
Quando se trabalha com dados de sobrevivência, é necessário conhecer o que é uma funcão de sobrevivência e como calculá-la, e en geral o que se procura é a distribuição do tempo de sobrevi vência.

LEE (1980) diz que a distribuição do tempo de sobrevivência é usualmente descrita ou caracterizada por três funcốes: (a) a funcão de sobrevivência; (b) a funçăo densidade de probabilidade; (C) a funcão de risco. Estas três funcõos são matematicamente equivalentes, isto é, se uma delas é dada, as outras duas podem ser deduzidas.

Na prática, estas três funções podem ser usadas para ilustrar diferentes aspectos dos dados.
\end{abstract}

2.1. Funçăo de sobrevi vencia

Segundo MILLER (1981), LAYLESS (1982) \& LEE (1980), a definicăo de função de sobrevivência, s, é dada por:

$S(t)=$ Probabilidade de um individuo não falhar ou viver até o tempo t, isto é, 
$S(t)=P(T>t)=1-P(T \leq t)=1-F(t)$, onde $T \geq 0$ é uma variável aleatória que mede o tempo de vida até a falha de uma unidade e F é a sua função de distribuicão que supõe-se continua com densidade $f$.

Na prática, a funçăo de sobrevivência pode ser estimada como a proporcăo de individuos que sobreviveram até o tempo t, isto é,

$$
\hat{S}(t)=\frac{n^{0} \text { unidades que sobrevi veram ate } 0 \text { tempot }}{n^{0} \text { total de unidades }} \text { (2.1) }
$$

onde $\hat{S}(t)$ denota uma estimativa de $S(t)$.

S(t) é também chamada de razão de sobrevivência acumulada. Para retratar a curva de sobrevivência, BERKSON (1942) recomenda uma representacão gráfica de $S(t)$. o gráfico de $S(t)$ é chamado de curva de sobrevi véncia.

2.2. Funçăo densidade de probabilidade (f.d.p.)

Segundo LEE (1980), o tempo de sobrevi vência T, assim como gualquer outra variável aleatória continua, tem uma f.d.p., f, que neste caso será definida como o limite da probabilidade de uma unidade falhar no intervalo 
[t; $t+\Delta t]$, dividido pela variacão de tempo, $\Delta t$, quando $\Delta t \rightarrow 0$, ou simplesmente, a probabilidade de falhar em um intervalo pequeno por unidade de tempo. Isto pode ser expresso por:

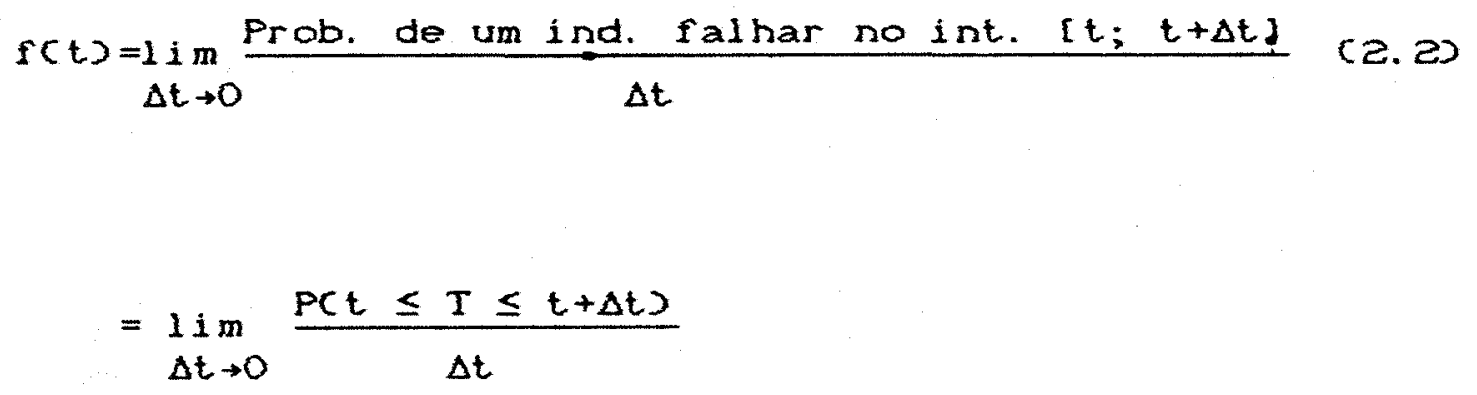

Segundo MILLER (1981), a funcão de risco h(t) do tempo de sobrevi vência I dá a razão de fal ha condicional. Esta funcão é definida como o limite da probabilidade de a unidade falhar entre os trempos $t e t+\Delta t$, dado que sobrevi veu até o tempo $t$, quando $\Delta t \rightarrow 0$, ou seja:

$$
h(t)=\lim _{\Delta t \rightarrow 0^{+}} \frac{P(t \leq T \leq t+\Delta t \mid T \geq t)}{\Delta t}
$$

Como está suposto que a funcão densidade de probabilidade de $T$ é $f$, então pode-se observar que:

$$
h(t)=\lim _{\Delta t \rightarrow 0^{+}} \frac{P(t \leq T \leq t+\Delta t \mid T \geq t)}{\Delta t}=
$$


B.

$$
=\lim _{\Delta t \rightarrow 0^{+}} \frac{P(t \leq T \leq t+\Delta t, T>t)}{\Delta t . P(T>t)}
$$

$$
\begin{array}{r}
\text { Como }\{t \leq T \leq t+\Delta t) c\{T>t\} \text { então } \\
P(t \leq T \leq t+\Delta t, T>t)=P(t \leq T \leq t+\Delta t), \text { daí } \\
h(t)=\lim _{\Delta t \rightarrow 0^{+}} \frac{F(t+\Delta t)-F(t)}{\Delta t} \cdot \frac{1}{S(t)}=\frac{f(t)}{S(t)}
\end{array}
$$

Então, tem-se que:

$$
h(t)=\frac{f(t)}{S(t)}=\frac{f(t)}{1-F(t)}
$$

Integrando $h(t)$ no intervalo $[0, t], t e m-s e:$

$$
\begin{aligned}
& \int_{0}^{t} h(u) d u=\int_{0}^{t} \frac{f(u)}{S(u)} d u=\int_{0}^{1} \frac{f(u)}{1-F(u)}= \\
& =-\log _{0}[1-F(u)]_{0}^{t}=-\log _{0}[1-F(t)]=-\log _{0} s(t)
\end{aligned}
$$


Daí, obtêm-se que

$$
s(t)=e^{-s_{0}^{t} \text { hou du }}
$$

Com isso, pode-se observar que:

$$
\lim _{t \rightarrow+\infty} s(t)=0 \quad \text { se } \int_{0}^{t} h(\omega) d u \rightarrow+\infty
$$

e

$$
\lim _{t \rightarrow 0^{+}} s(t)=1 \text { se } \int_{0}^{1} h(u) d u \longrightarrow 0
$$

Quando se está tratando de dados referentes a tempos de sobrevivencia, o maior problema surge quando, ao final do ensaio, nem todas unidades falharam. Neste caso, diz-se que estas unidades foram censuradas, e tem-se então um tempo de censura, cuja informacão teria que ser utilizada nas anălises.

Segundo BONFARINE et alii (1991), pode-se definir cada tipo de censura: 
8.

\section{4. Censura tipo I}

Neste tipo de censura, têm-se experimentos com um intervalo de tempo fixado. Uma possibilidade é considerar $n$ unidades no início do experimento e terminar o estudo após um periodo de tempo conhecido L. Neste caso, todas as unidades que não falharam terăo um tempo fixado de

censura. Una outra possibilidade é considerar um experimento onde cada unidade amostral tem seu tempo especifico de censura $L_{i}$ conhecido, pois nem todas as unidades precisam iniciar o teste na mesma data.

Sendo $L_{1}, \ldots, L_{n}$ os tempos de censura fixados para cada unidade, 0 tempo de vida $t_{i}$ da i-ésima unidade será observado se $T_{i} \leq L_{i}$.

Pode-se observar que com todos os tempos de censura $L_{i}$ iguais tem-se censura do tipo I simples e também notar que o número $r$ de unidades, cujos tempos de sobrevivência são observados, é uma variável aleatóría.

$$
\text { Sejam os tempos de vida } T_{1}, \ldots, T_{n} \text { variáveis }
$$

aleatórias independentes $\theta$ identicamente distribuidas com função densidade de probabilidade $f$ e funcão de sobrevivência $S$. O tempo exato de sobrevivência é observado somente se $T_{i} \leq L_{i}, i=1, \ldots, n$. Portanto, os dados observados são $\left(y_{i}, \delta_{i}\right)$, onde

$$
Y_{i}=\min \left(T_{i}, L_{i}{ }^{\prime}\right.
$$


$\Delta_{i}= \begin{cases}1 \text { se } T_{i} \leq L_{i} \text { (não houve censura) } \\ 0 \text { se } T_{i}>L_{i} \text { (houve censura) }\end{cases}$

Pode-se observar que $\Delta_{i} \&$ uma variável indicadora de censura.

A função de densidade de probabilidade conjunta para $Y_{i} e \Delta_{i}$ edada por:

$$
f\left(y_{i}, \delta_{i}\right)= \begin{cases}f^{\delta}\left(T_{i}\right) s^{1-\delta_{i}}\left(L_{i}\right) & \text { se } 0 \leq t_{i} \leq L_{i} \\ 0 & \text { sec.c. }\end{cases}
$$

Note-se que $Y_{i}$ é uma variável aleatória com função de distribuiça que sofre um salto em $L_{i}$ :

$$
P\left[Y_{i}=L_{i}\right]=P\left[\Delta_{i}=0\right]=P\left[T_{i}>L_{i}\right]=S\left(L_{i}\right)
$$

Para valores $Y_{i}<L_{i}, a$ funcăo de distribuiçåo conducionada de probabilidade de $Y_{i}$ dado que $\Delta_{i}=1$, e fornecida por: 
10.

$$
\begin{gathered}
P\left[Y_{i} \leq y_{i} \mid \Delta_{i}=1\right]=P\left[Y_{i} \leq t_{i} \mid Y_{i} \leq L_{i}\right]=\frac{P\left[Y_{i} \leq t_{i}, Y_{i} \leq L_{i}\right]}{P\left(Y_{i} \leq L_{i}\right]}= \\
=\frac{P\left[Y_{i} \leq t_{i}, \Delta_{i}=1\right]}{1-S\left(L_{i}\right)}=\frac{F\left[t_{i}\right)}{1-S\left[L_{i}\right]},
\end{gathered}
$$

Portanto,

$$
P\left[Y_{i}=L_{i}, \Delta_{i}=0\right]=P\left[\Delta_{i}=0\right]=S\left[L_{i}\right] \quad \text { (2.9) }
$$

$$
=\frac{F\left[t_{i}\right]}{1-S\left(L_{i}\right]} \cdot\left[1-S\left[L_{i}\right]\right)=F\left[t_{i}\right] \text { se } 0 \leq t_{i} \leq L_{i} \text { (2.10) }
$$

Derivando $F\left(t_{i}\right)$, encontra-se a funcão de densidade para a parte absolutamente continua de $f\left(y_{i}, \delta_{i}\right)$ como dado em (2. 6 ).

Se os pares $\left[\mathrm{T}_{i}, \Delta_{i}\right]$ são independentes, a função de verossimil hança é dada por: 


$$
L=\prod_{i=1}^{n}\left[f\left(t_{i}\right]\right]^{\sigma_{i}}\left[S\left(L_{i}\right)\right]^{1-\delta_{i}}
$$

\subsection{Censura tipo II}

Neste tipo de censura, somente as $r$ menores observacões ordenadas numa amostra aleatória de tamanho $n$ são observadas $(r$ fixo, $1 \leq r \leq n)$. Assim, podem-se colocar $n$ unidades em teste terminar o experimento após a ocorrência da $r$-ésima falha. O nümero de falhas $r$ é fixado antes da realizacão do experi mento.

A densidade conjunta das $r$ estatísticas de ordem $T_{(1)}, T_{(2)}, \ldots, T_{(r)}$ é dada por:

$f\left[t_{(1)}, \ldots, t_{(r)}\right]=\frac{n !}{(n-r) !} f\left[t_{(1)}\right] \ldots f\left[t_{(r)}\right) \cdot\left[S\left[t_{(r)}\right]\right]^{n-r}(2.12)$

onde a funcão $f(t)$ é a função densidade de probabilidade conjunta da variável aleatória $I$ e $t_{(T)}$ é o tempo de vida que corresponde à ocorrência da r-ésima falha. 


\subsection{Censura Aleatória}

os tempos de censura muitas vezes são aleatórios, ou seja, as unidades entram em estudo de forma aleatória. Se o estudo termina numa data pré-estabelecida, os tempos de censura são variáveis aleatórias. Frequientemente consideram-se censuras do tipo I assumindo dados condicionais nos tempos de censuras observados.

Seja T uma variável aleatória representando o tempo de sobrevi vência de uma unidade, e seja l uma variável aleatória representando o tempo de censura associado a esta unidade. Com censuras aleatórias, é comum a suposicão de que as variáveis aleatórias contínuas $T$ e sejam independentes com funcốes de sobrevi vências $S$ e $G$, respecti vamente.

$$
\text { Considerando os pares }\left[I_{i}, L_{i}\right], i=1, \ldots, n
$$

independentes, com

$$
Y_{i}=\min \left[T_{i}, L_{i}\right] \text { e a variável indicadora }
$$

$$
\Delta_{i}= \begin{cases}1 ; & T_{i} \leq L_{i} \\ 0 ; & T_{i}>L_{i}\end{cases}
$$

os dados observados serão os pares $\left[Y_{i}, \Delta_{i}\right), i=1, \ldots, n$. 
13.

Supondo que $f$ g sejam as funçóes densidade de $T_{i}$ e $L_{i}$ respectivamente, tem-se que:

$$
f\left(y_{i}, \delta_{i}\right)=\lim _{\Delta y_{i} \rightarrow 0} \frac{P\left[y_{i} \leq y_{i} \leq y_{i}+\Delta y_{i}, \Delta \Delta_{i}\right]}{\Delta y_{i}}
$$

Mas,

$$
\begin{aligned}
& P\left[y_{i} \leq y_{i} \leq y_{i}+\Delta y_{i}, \Delta_{i}=1\right]= \\
= & P\left[y_{i} \leq T_{i} \leq y_{i}+\Delta y_{i}, L_{i} \geq T_{i}\right] \cong \\
\cong & P\left[y_{i}\right]\left[G\left[y_{i}\right]\right] \Delta y_{i} \\
& P\left[y_{i}<Y_{i} \leq y_{i}+\Delta y_{i}, \Delta=0\right]= \\
= & P\left[y_{i}<L_{i} \leq y_{i}+\Delta y_{i}, L_{i}<T_{i}\right] \cong \\
\cong & g\left[y_{i}\right]\left[1-F\left[y_{i}\right]\right] \Delta y_{i}
\end{aligned}
$$

Passando o limite, tem-se que:

$$
f\left(y_{i}, \delta_{i}\right]=\left\{\begin{array}{l}
f\left(y_{i}\right]\left[G\left(y_{i}\right)\right] \quad \text { se } \Delta_{i}=1 \\
g\left(y_{i}\right)\left[1-F\left(y_{i}\right)\right]=g\left(y_{i}\right) s\left(y_{i}\right) \text { se } \Delta_{i}=0
\end{array}\right.
$$


14.

Logo, pode-se escrever a função de densidade de probabilidade de $\left[Y_{i}, \Delta_{i}\right]$ da seguinte forma:

$$
\left.\left.\left.f\left[y_{i}, \delta\right)=\left[f\left(y_{i}\right) \alpha c y_{i}\right)\right]^{\delta}\left[g x y_{i}\right) s c y_{i}\right)\right]^{1-\delta}
$$

Portanto, a funcão de verossimilhanca de $\left[Y_{i}, \delta_{i}\right], i=1, \ldots, n$ é dada por:

$$
\begin{aligned}
& L=\prod_{i=1}^{n}\left[f\left[y_{i}\right) G\left(y_{i}\right]\right]^{\delta}\left[g\left(y_{i}\right) S\left(y_{i}\right)\right]^{1-\delta_{i}}= \\
& =\prod_{i=1}^{n} f^{\delta_{i}}\left(y_{i}\right) s^{1-\delta_{i}}\left(y_{i}\right) g^{1-\delta_{i}}\left[y_{i}\right) \sigma^{\delta_{i}}\left[y_{i}\right]
\end{aligned}
$$

Como em geral tem-se interesse en parâmetros associados ao tempo de sobrevi vêncla I Cque não aparecem em G), considera-se a funcão de verossimil hanca dada por:

$$
L=\prod_{i=1}^{n} f^{\delta_{i}}\left[y_{i}\right] s^{1-\delta_{i}}\left[y_{i}\right]
$$

A f unção de sobrevi vência $S$ pode ser estimada por métodos paramétricos não-paramétricos para o caso em que os tempos de vida observados apresentam censura. 
Veremos a seguir alguns métodos mais utilizados para estimar $S(t)$

2.7. Métodos năo-paramétricos para estimaçấo das funçốes de sobrevi vencia

\subsubsection{Metodo atuarial}

Ainda segundo BONFARINE et alii (1991), pode-se usar o método atuarial ou método da tabela de vida para se estimar $S$, apresentando a informacão sobre a sobrevi vência de um grupo de unidades submetidas a um determinado tratamento.

Essas tabelas são generalizaçóes de tabelas de freqüências relativas quando tem-se dados censurados, isto é, os dados são agrupados de tal forma que tem-se apenas informaçós sobre em quais intervalos as unidades falharam ou foram censuradas, e não se sabe o tempo exato de sobrevi vência ou censura de cada unidade.

De acordo com os autores citados acima, para estimar a funçăo de sobrevi vência, o mótodo atuarial supöe que o período de observacão de $n$ individuos seja $[0, t\}$ e que este intervalo seja seccionado nos tempos $0=a_{0}<a_{1}<\ldots<a_{k}=t<a_{k+1}=\infty$ Em cada intervalo $I_{j}=\left[a_{j-1} ; a_{j}\right]$ calculam-se estimativas das probabilidades 
condicionais de a falha ocorrer neste intervalo, dado que a unidade não fal hou até $a_{j-1}$, isto é,

$$
\begin{aligned}
q_{i}=P\left[T_{i} \leq a_{j} \mid T_{i}>a_{j-1}\right]=\frac{P\left[a_{j-1} \leq T_{i} \leq a_{j}\right]}{P\left[T_{i}>a_{j-1}\right]}= \\
=\frac{F\left[a_{j}\right]-F\left[a_{j-1}\right]}{1-F\left[a_{j-1}\right]}
\end{aligned}
$$

de modo que,

$$
P_{i}=1-q_{j}=P\left[T_{i}>a_{j} \mid T_{i}>a_{j-1}\right]=\frac{S\left(a_{j}\right)}{S\left[a_{j-1}\right]}
$$

onde $p_{i}$ é a probabilidade condicional de 0 individuo não falhar até $a_{j}$ Daí, a função de sobrevivência em $a_{j}$ $j=1, \ldots, k+1$ é dada por:

$S\left[a_{j}\right]=P\left[I>a_{j}\right]=P\left[I>a_{1} \mid T>a_{0}\right] \cdot P\left[I>a_{2} \mid T>a_{1}\right] \ldots$ 


$$
\begin{aligned}
& \ldots P\left[T>a_{j} \mid T>a_{j-1}\right]=\frac{P\left[T>a_{1} \cap T>a_{0}\right]}{P\left[T>a_{0}\right]} \cdot P\left[I>a_{2} \mid T>a_{1}\right] \\
& \ldots P\left[I>a_{j} \mid I>a_{j-1}\right]=P\left[I>a_{1}\right] \cdot P\left[I>a_{2} \mid I>a_{1}\right] . \\
& \cdots P\left[I>a_{j} \mid T>a_{j-1}\right]=P_{1} \cdot P_{2} \cdots P_{j}=\underset{i=1}{j} P_{i}
\end{aligned}
$$

Então, o estimador atuarial de $S\left[a_{j}\right)$ é dado por:

$$
\hat{S}\left(a_{i}\right)=\prod_{i=1}^{j} \hat{p}_{i}, j=1, \ldots, k+1
$$

$\operatorname{com} \hat{p}_{i}=1-\hat{q}_{i}$ e $\hat{q}_{i}=\frac{D_{i}}{N_{i}-H_{i} / 2}$, onde $D_{i}$ é número de unidades que falharam em $I_{i}, N_{i} e$ o número de unidades em risco em $I_{i} e W_{i}$ é o número de censuras no intervalo $I_{i}$.

LIMA (1988) prova os seguintes teoremas sobre. a distribuição assintótica de $\hat{q}_{i}$ e $\hat{S}\left[a_{i}\right]$ : 
Teorema 1.

$$
\sqrt{n}\left[\hat{q}_{j}-q_{j}^{*}\right] \stackrel{D}{\longrightarrow} N[0, \Sigma)
$$

onde $q_{j}^{*}=\frac{\pi_{j}^{D}}{\pi_{j}^{N}-1 / 2 \pi_{j}^{w}}, \operatorname{com} n_{j}^{D}, \Pi_{j}^{N} \in \Pi_{j}^{W}$, representando,

respectivamente, as probabilidades de fal ha, de unidades em risco de censura no intervalo $I_{j}$ a matriz de covariancia $\Sigma$ é a diagonal, cujos elementos são dados por:

$$
\left[n_{k}^{N}-1 / 2 n_{k}^{w}\right]^{-1}\left[q_{k}^{*}-\left[q_{k}^{*}\right]^{2} \frac{n_{k}^{N}-1 / 4 n_{k}^{w}}{n_{k}^{N}-1 / 2 n_{k}^{*}}\right], k=1, \ldots, j
$$

Teorema 2.

$$
\sqrt{n}\left[S\left[a_{j}\right]-S^{*}\left[a_{j}\right)\right] \stackrel{D}{\longrightarrow} N[0, \Sigma]
$$

onde $\boldsymbol{\Sigma}$ é uma matriz de covariância com elementos dados por: 
19.

$$
s^{*}\left[a_{k}\right] s^{*}\left[a_{l}\right] \sum_{j=1}^{n} \operatorname{var} \frac{\left[\sqrt{n}\left[\hat{a}_{j}-q_{j}^{*}\right)\right]}{\left(1-q_{j}^{*}\right]^{2}}, k \leq l
$$

onde $S^{*}\left[a_{1}\right]=\prod_{j=1}^{i}\left[1-q_{j}^{*}\right]$, e $\hat{S}\left[a_{j}\right]$ é o estimador atuarial da função de sobrevi vência $S\left[a_{j}\right]$.

\subsubsection{Estimador Produto Limite de Kaplan-Meler}

- estimador do produto 1 imite, $\hat{S}_{k m}(t)$, foi proposto por Böhner (1912), e suas propriedades foram estudadas muitos anos depois por KAPLAN \& MEIER (1958), sendo por isso também conhecido como estimador de KAPLAN-MEIER $C K-M D$

${ }^{1}$ BöHMER, P. E. Theorie der unabhangingens wahrscheinilichkeiten Rapports, Memorieset proces-Verbaux deseptieme Congress International d'actuaries, Amsterdan, 2: $327-343,1912$. 
Este estimador é uma importante ferramenta para análise de dados de sobrevi vência com censuras e tem-se mostrado preciso em ensaios onde se têm perdas de segmento Cnão se obtêm informacốes a respeito da unidade a partir de um certo tempos e en ensaios onde se termina o estudo sem que todas unidades tenham fal hado.

Segundo BONFARINE et alii (1991) o estimador de Kaplan-Meier pode ser visto como o caso limite dos estimadores da tabela de vida padrão quando o número de particôes no intervalo $[0, t]$ tende a infinito.

Considerando $n$ individuos e $k \leq n$ tempos distintos, $t_{1}, \ldots, t_{k}$, onde ocorrem mortes ou falhas, observa-se que pode ocorrer mais de uma falha no tempo $t_{j}$ Seja $D_{j}$ o número de fal has em $t_{j}$.

Sendo $D_{j} \leq 1$, temos que $N_{j}=n-j+1 \Leftrightarrow 0$ número de unidades em risco em $t_{j}$, e assim:

$$
1-\hat{q}_{j}=\left\{\begin{array}{cl}
1-\frac{1}{N_{j}} ; \delta_{j} & =1 \text { (não houve censura) } \\
1 \quad & ; \delta_{j}=0 \text { (houve censura) }
\end{array}\right.
$$

para $j=1, \ldots$ n. Portanto, a funcão de sobrevi vência será estimada por:

$$
\hat{S}_{k m}(t)=\prod_{j i t i k t}\left(1-\hat{q}_{j}\right)^{\delta}=\prod_{j ; i_{j}<t}\left(1-\frac{1}{N_{j}}\right)^{\delta_{j}}=
$$


21.

$$
=\pi_{j ; t<i}\left(\frac{N_{j}-1}{N_{j}}\right)^{\delta_{j}}=\Pi_{j, i}{ }_{j}^{\alpha t}\left(\frac{n-j}{n-j+1}\right)^{\delta}
$$

Quando $D_{j}>1$, para alguns instantes, $\hat{S}_{k m}(t)$ pode ser reescrita considerando-se que as $D_{j}$ falhas que ocorrem no mesmo instante podem ser separadas por um refinamento maior na particão en $[0, t]$, de modo que a probabilidade condicional de sobrevi vência será dada por:

$$
1-\hat{q}_{j}=\frac{N_{j}-1}{N_{j}} \frac{N_{j}-2}{N_{j}-1} \cdots \frac{N_{j}-D_{j}}{N_{j}-D_{j}+1}=\frac{N_{j}-D_{j}}{N_{j}}
$$

Portanto, no caso de empates, o estimador de K-M para a funcão de sobrevi vência será:

$$
\hat{S}_{x m}(t)=\Pi_{j ; t<i}\left(\frac{N_{j}-D_{j}}{N_{j}}\right)^{\delta}
$$


Quanto às propriedades assintóticas do estimador de Kaplan-Meier, em BONFARINE et ali $i$ têm-se os seguintes teoremas:

Teorema 3. 0 estimador $\hat{S}_{k m}(t)$ é fortemente consistente para $S(t)$, ou seja, $\hat{S}_{k m}(t) \stackrel{\text { q.c. }}{\longrightarrow} s(t)$ $\left[\hat{S}_{k m}(t)\right.$ converge quase certamente para $\left.S(t)\right]$

Prova: Omitida.

Teorema 4. Supondo que $T<\infty$ que $F($.$) \in($.$) são funcỗes$ de distribuição, a função aleatória $\sqrt{n}\left[\hat{S}_{k m}(t)-S(t)\right], 0<t<T$, converge fracamente para um processo gaussiano $Z^{\circ}(t)$ com média zero e variância de $\hat{S}_{k m}(t)$ dada aproximadamente por :

$\operatorname{var}\left[\hat{S}_{k m}(t)\right] \cong \frac{1}{n}(s(t))^{2} \int_{0}^{1} \frac{d F(u)}{\left(1-d(u)(s(u))^{2}\right)}(2.21)$

No caso de não haver empates tem-se:

$$
\left.\operatorname{var}\left[\hat{S}_{x m}(t)\right]=(\hat{S}(t)]^{2} \sum_{i ; \pi i \leq t} \frac{\delta_{i}}{(n-i)(n-i+1)} \quad \text { (2. } 22\right)
$$


23.

E no caso de empates:

$$
\operatorname{Var}\left[\hat{S}_{k m}(t)\right]=\frac{1}{n} \sum_{j ; t} \leq i \frac{D_{j}}{N_{j}\left(N_{j}-D_{j}\right)}
$$

Prova: Omitida.

Segundo LEE (1980), o tempo médio de sobrevivência $\mu$ pode ser estimado como a média das estimativas de Kaplan-Meier. Se os tempos de morte são ordenados como $t_{(1)} \leq t_{(z)} \leq \ldots \leq t_{(m)}$ cse há $m$ observacões não censuradas $)$ e $t_{(m)}$ é a maior observacão das $n$ observacões cisto é, $t_{(m)}=t_{(n)}$ quando $t_{(n)}$ é observacão não censuradas, então $\mu$ pode ser estimada por:

$\mu=1,00 t_{(1)}+\hat{S}\left[t_{(1)}\right]\left(t_{(2)}-t_{(1)}\right)+\ldots+\hat{S}\left[t_{(m-1)}\right]\left[t_{(m)}-t_{(m-1)}\right)$

No entanto, se a maior observação entre todas as $n$ observaçóes é censurada e é usada como $t_{(m)}$ na equacão (2. 24), $\mu$ assim obtido pode ser uma subestimativa. Nestes casos, IRYIR (1949) diz que em vez de se estimar o tempo médio de sobrevivência deve-se escolher um tempo limite L e estimar o "tempo médio de sobrevi vência limitado a um tempo $L “$, dito $\mu_{(L)}$, trocando $t_{(m)}$ por $L$ na equacão $(2.24)$. 
variância de $\mu$ é estimada por:

$$
\hat{\operatorname{Var}}(\hat{\mu})=\sum_{r} \frac{A_{r}^{2}}{(n-r)(n-r+1)}
$$

onde $r$ percorre os inteiros para os quais $t$ (r) corresponde a uma morte, e $A_{r}$ é a área sob a curva $\hat{S}(t)$ a direita de $t_{(r)}$. o k-ésimo $A_{r}$ em termos das $m$ abservacóes não censuradas é:

$$
\begin{aligned}
& \hat{S}\left[t_{(k)}\right]\left[t_{(k+1)}-t_{(k)}\right]+\hat{S}\left(t_{(k+1)}\right]\left[t_{(k+2)}-t_{(k+1)}\right]+\ldots \\
& \ldots+\hat{S}\left[t_{(m-1)}\right]\left[t_{(m)}-t_{(m-1)}\right] .
\end{aligned}
$$

Se não há observações censuradas no conjunto de dados, a equação (2. 24$)$ reduz-se à média amostral,

$$
\bar{t}=\frac{\Sigma t_{i}}{n}
$$

e a equacão (2. 25$)$ reduz-se a

$$
\hat{\operatorname{var}}(\hat{\mu})=\hat{\operatorname{var}}(\bar{t})=\frac{\sum\left(t_{i}-\bar{t}\right)^{2}}{n^{2}}
$$

É comum na experimentacão estarmos interessados em testar a diferenca entre os tratamentos. Com 
dados de sobrevivência isso também pode ser feito. Uma maneira é comparar as funcões de sobrevi vência de ambos e verificar o seu desempenho, ou seja, considerando um ensaio com dois tratamentos (duas populacões) pode-se estimar a função de sobrevi vência para cada tratamento e comparar tais funcões.

Para isto, tem-se os seguintes testes não paramétricos:

2.8. Testes năo-paramétricos para comparar duas funçós de sobrevi vencia

2. 8.1. Teste de GEHAN (1965a) (uma generalizaçăo do teste de Wilcoxon

Seja $x_{i}=\min \left\{T_{i}, L_{i}\right\}, i=1, \ldots, n_{1}$, valores observados das unidades da populacão 1 , onde se supõe que $T_{i}$ seja o tempo de falha com funcão de distribuicão $F_{1}$ e que $L_{i}$ seja o tempo de censura com funcão de distribuicão $G_{1} ; e$ seja também $Y_{j}=\min \left(D_{j}, C_{j}\right)$ $j=1, \ldots, n_{2}$, valores observados das unidades da populacão 2 , onde $D_{j}$ representa o tempo de falha com funcão de distribuicão $F_{z}$, e $C_{j}$ representa o tempo de censura com funcão de distribuicão $G_{z}$.

GEHAN (1985a) supõe que as hipóteses sejam $H_{0}: F_{1}(t)=F_{2}(t)$ vs $H_{1}: F_{2}(t)<F_{2}(t)$ ou $H_{0}: S_{1}(t)=$ 
20.

$S_{2}(t)$ vs $H_{1}: S_{1}(t)>S_{2}(t)$, onde $S_{1}(t)$ e $S_{2}(t)$ são as funções de sobrevivência da populacão 1 e 2 , respecti vamente.

Define-se:

$$
U_{i j}=\left\{\begin{array}{l}
1 \text { se }\left(x_{i}>y_{j}, \varepsilon_{i}=1\right) \text { ou }\left[x_{i}=y_{j}, \delta_{i}=0, \varepsilon_{j}=1\right] \\
0 \text { se caso contrário } \\
-1 \text { se }\left[x _ { i } \langle y _ { j } , \delta _ { i } = 1 ] \text { ou } \left[x_{i}=y_{j}, \delta_{i}=1, \varepsilon_{j}=0\right.\right.
\end{array}\right.
$$

onde $\delta_{i} e$ o indicador de censura da população $1 \propto \varepsilon_{j}$ é indicador de censura da população 2 .

$$
\text { A estatística do teste é: }
$$

$$
W=\sum_{j=1}^{n_{2}} \sum_{i=1}^{n_{1}} U_{i j},
$$

onde a soma é sobre toda comparacão $n_{1} n_{2}$.

Se a hipótese $H_{0}$ é verdadeira, pode-se mostrar que tem uma distribuição assintoticamente normal com média zero. Para a variância de $W$, arranjaram-se, em ordem crescente, observacões não censuradas distintas de dois grupos e então foram colocados sous postos. Seja $m_{i}$ o número de observacóes não censuradas de posto $i, m_{i} \geq 1$ e seja $t_{i}$ o número de observacóes censuradas com valores 
maiores do que as observações não censuradas de posto i, mas menor que as observaçóes de posto $(i+1)$. A variância de $w$ sob $H_{0}: F_{1}(t)=F_{2}(t)$ é:

$\operatorname{Var}(w)=\frac{n_{1} n_{2}}{\left(n_{1}+n_{2}\right)\left(n_{1}+n_{2}-1\right)} \cdot\left\{\sum_{i=1}^{k} m_{i} M_{i-1}\left(M_{i-1}+1\right)+\right.$

$+\sum_{i=1}^{k} \ell_{i} M_{i}\left[M_{i}+1\right]+\sum_{i=1}^{k} m_{i}\left[n_{1}+n_{2}-t_{0}-m_{i}-L_{(i-1)}\right] \cdot\left[n_{1}+\right.$

$\left.\left.n_{2}-l_{0}-3 M_{i-1}-m_{i}-L_{i-1}-1\right)\right\}$

onde $x$ é o número de observações não censuradas distintas e

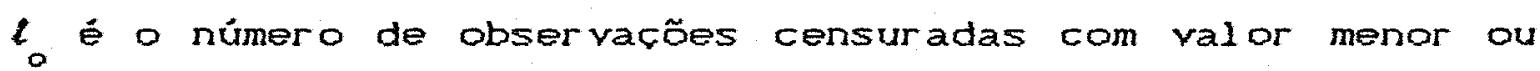
i gual à menor observação não censurada, com:

$$
M_{j}=\sum_{i=1}^{j} m_{i} ; M_{0}=O ; L_{j}=\sum_{i=1}^{j} t_{i} ; L_{0}=0
$$

Os cálculos de We de varChy são trabal hosos quando $n_{1}$ e $n_{2}$ são grandes. MANTEL (1967) mostra que a estatística $\%$ pode ser calculada de modo alternativo atribuindo um escore para cada observacão baseado nos postos relativos. 
28.

Em GEHAN (1905b) cada obser vação da amostra 1 - comparada com cada observacão da amostra 2 . Se as amostras são combinadas em uma amostra simples de $\left[n_{1}+n_{2}\right)$ observacôes, é o mesmo que comparar cada observacão com as $\left(n_{1}+n_{2}-1\right)$ obser vacões.

Se não há empates ou falhas, isto é, $m_{1}=$ $m_{2}=\ldots=m_{k}=1$ e $k=n_{1}+n_{2}$, a equacão da variância de $w$ fica:

$$
\operatorname{Var}(y)=\frac{1}{3} n_{1}+n_{2}\left(n_{1}+n_{2}+1\right)
$$

Se não há empates e todas as observacỗes são

$$
\begin{aligned}
& \text { censuradas após } \mathrm{Cr}_{1}+\mathrm{r}_{2}{ }^{\mathrm{s}} \text { falhas, isto é, } \\
& m_{1}=m_{2}=\ldots=m_{k}=1, \quad t_{1}=t_{2}=\ldots=t_{k-1}=0, \\
& l_{x}=n_{1}-r_{1}+n_{2}-r_{2} e k=r_{1}+r_{2} \text {, tem-se: } \\
& \operatorname{Var}(w)=\frac{n_{1} \cdot n_{2}\left(r_{1}+r_{2}\right)}{\left(n_{1}+n_{2}\right)\left(n_{1}+n_{2}-1\right)} \cdot\left\{\left(n_{1}+n_{2}\right)\left(n_{1}-r_{1}+n_{2}-r_{2}\right)+\right. \\
& \left.+\frac{1}{3}\left[\left[r_{1}+r_{2}\right]^{2}-1\right]\right\}
\end{aligned}
$$


29.

\subsubsection{Teste "Logrank"}

Segundo PETO \& PETO (1972) o teste "Logrank" é baseado em um conjunto de escores $\mathbb{F}_{i}$ designados a várias observacões. Os escores são funcões do logaritmo da função de sobrevivência, e, segundo Altshuller ${ }^{1}$, citado em LEE (1980), uma estimativa desses escores é dada por:

$$
\delta\left[t_{(i)}\right]=\sum_{j\left\langle t_{(i)}\right.} \frac{m_{(j)}}{r_{(j)}},
$$

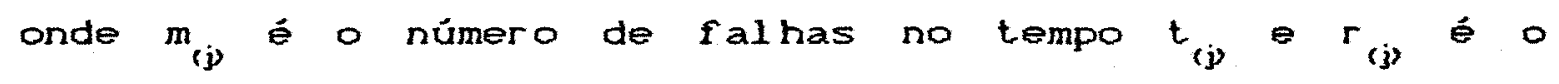
número de falhas ou censuras no conjunto de unidades cujo tempo de falha é menor que $t_{i}$.

$$
\text { os escores são } w_{i}=B\left[t_{(i)}\right]-1 \text { para uma }
$$

observacão não censurada em $t_{i} e w_{i}=s\left[t_{i},{ }\right)$ para uma observacão censurada. Desta maneira, a maior observação censurada é o maior escore. Observacões não censuradas recebem escores negativos. A soma dos escores $\%$ dos dois grupos juntos é identicamente igual a zero. o teste "Logrank" é baseado na somas dos escores $W$ em um dos dois grupos. A variância de $S$ é dada por:

${ }^{1}$ ALTSHULER, B. Theory for the measurement of competing risks in animal experiments. Mathematical Biosciences, B: $1-11,1970$. 
30 .

$$
v=n_{1} n_{2} \sum_{i=1}^{n_{1}+n_{2}} \frac{w_{i}^{2}}{\left(n_{1}+n_{2}\right)\left[n_{1}+n_{2}-1\right)}
$$

que pode ser reescrita como:

$$
V=\left\{\sum_{j=1}^{k} \frac{m_{j} c r_{j}-m_{j}>}{r_{j}}\right\} \frac{n_{1} n_{2}}{\left[n_{1}+n_{2}\right)\left[n_{1}+n_{2}-1\right)}
$$

Pode-se mostrar que a estatística do teste $L=S / \sqrt{V}$, onde $S=\sum_{i=1}^{n} w_{i}$ de um dos dois grupos, tem, sob $H_{0}$ : $F_{1}(t)=F_{2}(t)$, uma distribuicão assintoticamente normal padrão.

\subsubsection{Teste de Mantel e Haenszel (1959)}

Quando os dados de sobrevi vência são arranjados em forma de tabela de vida padrão, MANTEL \& HAENSZEL (1959) sugerem um teste qui quadrado para comparacão de duas distribuicoóes de sobrevi vência.

Seja $n_{j i}$ o número de individuos no grupo $\mathfrak{j}, \mathfrak{j}=1,2$, exposto ao risco no $i$-ésimo intervalo $i=1,2$, $\ldots, s, d_{j i}$ o número de mortes no grupo $j$ no $i$-ésimo intervalo. Para cada um dos s intervalos, os dados podem ser representados por uma tabela de contingência 2xe da forma: 
31.

\begin{tabular}{c|c|c|c}
\hline & $\begin{array}{c}\text { Número de } \\
\text { mortes }\end{array}$ & $\begin{array}{c}\text { Numero de } \\
\text { Sobrevi ventes }\end{array}$ & Total \\
\hline Grupo 1 & $d_{1 i}$ & $n_{1 i}-d_{1 i}$ & $n_{1 i}$ \\
\hline & $d_{2 i}$ & $n_{2 i}-d_{z i}$ & $n_{z i}$ \\
\hline & $D_{i}$ & $S_{i}$ & $T_{i}$ \\
\hline
\end{tabular}

A estatística do teste de qui-quadrado, sem correcăo de continuidade, a qual permite uma comparacão simultânea sobre todas as $s$ tabelas de contingências para os 2 grupos, é dada por:

$$
x^{2}=\frac{\left.\int \sum_{i=1}^{s} d_{1 i}-\sum_{i=1}^{s} E\left(d_{1 i}\right)\right]^{2}}{\sum_{i=1}^{3} \operatorname{Var}\left(d_{1 i}\right)}
$$

onde:

$$
\begin{aligned}
& E\left[d_{1 i}\right]=\frac{n_{1 i} D_{i}}{T_{i}} \\
& \operatorname{var}\left(d_{1 i}\right]=\frac{N_{1 i} n_{2 i} D_{i} S_{i}}{T_{i}^{2}\left(T_{i}-1\right)}
\end{aligned}
$$

são as médias e variâncias, respectivamente, do número de mortes do grupo i, calculadas condicionalmente sobre o total marginal da tabela de contingência. Esta estatística segue a distribuição de $x^{2}$ com 1 g.1. Desta maneira, se um valor de 
32.

quiquadrado calculado é maior que o valor tabelado para um nivel de significância escolhido, indica uma diferença significativa entre os dois grupos.

2.9. Modelos parametricos para estimaça de funçáo de sobrevi vencia

Antes de se entrarem nos modelos paramétricos propriamente ditos, serão feitas algumas consideracóes gerais a respeito da estimacão paramétrica de função de sobrevi vência.

BONFARINE et ali (1991) consideram a situacão onde os tempos de vida correspondem a valores de uma variável aleatória associada a uma distribuicão de probabilidade conjunta F, indexada pelo vetor de parâmetros $\theta=\left(\theta_{1}, \ldots, \theta_{k}\right)$, pertencente a um espaco paramétrico subconjunto de $\mathbb{R}^{k}$, isto $b$, F pertence a uma classe de distribuicôes $T$, tal que:

$$
\tau=\left\{F_{\theta} ; \underset{\sim}{\theta} \in \mathbb{R}^{k}\right\}
$$

- consideram que o problema de estimacão da funcão de sobrevi vência pode ser colocado da seguinte maneira: 
33.

i) É dada uma função de valores reais-g com domínio no espaco paramétrico e cujo valor em $\theta$ precisa ser esti mado.

ii) Tem-se uma quantidade aleatória $T=\left[T_{1}, \ldots, T_{n}\right]$, distribuída de acordo com $F_{\theta}$, que pertence à classe $\tau$. Os valores efetivamente observados estão ordenados e constituem a variável $Y_{i}=\min \left[T_{i}, L_{i}\right]$, associados com os indicadores

$$
\delta_{i}=I_{\left[\tau_{i} \leq L_{i}\right]}
$$

i il) Através do método de máxima verossimilhanca (M.V.) será obtido um valor $\hat{\theta}$ para $\underset{\sim}{\theta}$. Usando a invariância do método de M.V., obtém-se o estimador de M.V., $\hat{S}_{\theta}(t)$ $\operatorname{para} S_{\theta}(t)$

Supondo que as variáveis aleatórias $I_{i}$ e $L_{i}$

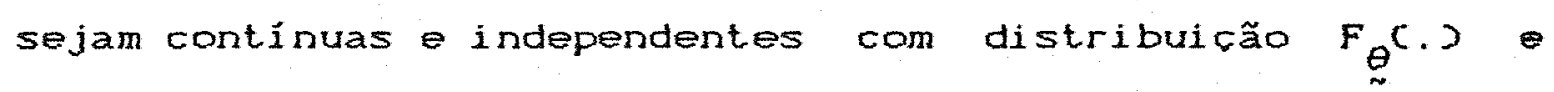
G. J, respecti vamente, as derivadas dessas funcões fornecem as densidades $f_{\theta}() \quad g.()$, que irão compor a verossimilhanca que é dada por:

$L\left(y_{i}, \theta\right)=\prod_{i=1}^{n}\left[f_{\theta}\left(y_{i}\right)\right]^{\delta}\left[1-F_{\theta}\left(y_{i}\right)\right]^{1-\delta_{i}}\left[g\left(y_{i}\right)\right]^{1-\delta_{i}}\left[1-\left(x y_{i}\right)\right]^{\delta}$ 


$$
=\prod_{i=1}^{n}\left[f_{\theta}\left(y_{i}\right)\right]^{\delta}\left[S_{\theta}\left(y_{i}\right)\right]^{1-\delta_{i}} \prod_{i=1}^{n}\left[g\left(y_{i}\right)\right]^{1-\sigma_{i}}\left[1-G\left(y_{i}\right)\right]^{\delta_{i}}
$$

conforme já visto em (2.14).

Como a distribuição de $L_{i}$ não contém parâmetro de interesse, então pode-se considerar a função de M. V. da seguinte forma:

$$
L\left(y_{i}, \theta\right)=\prod_{i=1}^{n}\left[f_{\underset{\sigma}{\theta}}\left(y_{i}\right)\right]^{\delta}\left[S_{\underset{\theta}{\theta}}\left(y_{i}\right)\right]^{1-\delta}
$$

de acordo com $(2.15)$ e tomando-se o logaritmo de $L\left(Y_{i}, \theta\right)$, obtém-se:

$$
\left.x y_{i}, \theta\right)=\log \left(L\left(y_{i}, \theta\right)=\sum_{i=1}^{n}\left[\delta_{i} \log \left(f_{\theta}\left(y_{i}\right)\right]+\left(1-\delta_{i}\right) \log \left(S_{\theta}\left(y_{i}\right)\right]\right]\right.
$$

Calculando-se a derivada parcial de $2\left(y_{i}, \theta\right)$ em relacão aos parâmetros $\theta_{i}$, igualando a zero, e testando pela $2^{a}$ derivada, têm-se os EMV para os $\theta_{i}$ 's.

No entanto, na maior parte das vezes, a maximizacão de $L\left(y_{i}, \theta\right)$ é feita através de métodos iterativos, como por exemplo, o método de Newton-Raphson, que é descrito a seguir. 


$$
\begin{aligned}
& w=\left(w_{1}, \ldots, w_{k}\right)^{\prime}, \text { onde } \\
& w_{j}=w\left(\theta_{j}\right)=\frac{\partial l\left(y_{i}, \theta\right)}{\partial \theta_{j}}, j=1, \ldots, k \theta
\end{aligned}
$$

$J=\left[J_{i j}\right]$, a matriz quadrada de dimensão $k$, onde

$$
J_{i j}=J\left[\theta_{i}, \theta_{j}\right]=\frac{\partial^{2} \ell\left(y_{i}, \theta\right)}{\partial \theta_{i} \partial \theta_{j}}, i, j=1, \ldots, k,
$$

que neste caso é a funcão de informacão amostral calculada em $\left[\underset{\sim i}{\theta_{i}}, \underset{\sim j}{\theta}\right)$. O vetor $W$ é costumeiramente chamado de escores cou funcão escores. Seja $\theta_{\sim}^{0}=\left(\theta_{1}^{0}, \ldots, \theta_{k}^{0}\right)$, um vetor coluna de dimensão $k$ cujos componentes estão próximos dos componentes de $\theta$. Expandindo $W$ em série de Taylor em torno de $\theta^{\circ}$, tem-se que:

$$
W(\underset{\sim}{\theta}) \cong\left(\dot{\sim}^{\circ}\right)+J\left({\underset{\sim}{\theta}}^{\circ}\right)\left(\underset{\sim}{\theta}-\underline{\sim}^{\circ}\right)
$$

Supondo $J$ não singular, pode-se escrever:

$$
\hat{\theta}=\underline{\sim}^{0}+J^{-1}\left(\underline{\sim}^{\circ}\right)\left[w(\hat{\theta})-w\left(\dot{\sim}^{\circ}\right)\right]
$$


Se $\hat{\theta}$ estiver suficientemente próximo do estimador de M.V. de $\underset{\sim}{\theta}$, a expressão pode ser escrita como:

$$
\hat{\theta}={\underset{\sim}{\theta}}^{0}-J^{-1}\left({\underset{\sim}{\theta}}^{0}\right) W\left(\underset{\sim}{\theta^{0}}\right)
$$

que fornece a base do processo iterativo, isto e, atraves do valor inicial $\theta_{\sim}^{\circ}$ obtém-se o valor $\underset{\sim}{\theta}$. A quantidade obtida considerada como o valor inicial da iteraçăo seguinte.

- processo continua ate satisfazer algum criterio de parada, como por exemplo, $\left\|\underset{\sim}{\hat{\theta}}-{\underset{\sim}{\theta}}^{0}\right\|<\varepsilon$, para algum $\varepsilon>0$. Quando existem problemas com a convergéncia do algoritmo, uma das modificaçōes mais comun é a substituição da matriz J pelo inverso da matriz de informaçăo de Fisher (BONFARINE et alii, 1991).

obtendo-se o estimador de M.V. $\underset{\sim}{\hat{\theta}}$ de $\underset{\sim}{\theta}$, segue da propriedade da invariancia do estimador de M.V. que

$$
\hat{S}_{\underset{\sim}{\theta}}(t)=S_{\underset{\sim}{\theta}}(t)
$$

No caso uniparametrico, assumindo que a funçă de densidade de probabilidade de $T \Leftrightarrow f_{\theta}^{(t)}$, tem-se que o estimador de M.V. $\hat{\theta}$ efortemente consistente e

$$
\sqrt{n}(\hat{\theta}-\theta) \stackrel{D}{\longrightarrow} N\left[0, I^{-1}(\theta)\right), \text { quando } n \longrightarrow \infty,
$$


37.

onde:

$$
I(\theta)=E\left[\frac{\partial \log f_{\theta}(r)}{\partial \theta}\right]^{2}=-E[J(\theta)]=-E\left[\frac{\partial^{2} \log f_{\theta}(r)}{\partial \theta^{2}}\right](2.34)
$$

é a informação de Fisher.

Segundo LEITE \& SINGER (1990), tem-se ainda o seguinte teorema:

Teorema 5. Se $\hat{f}_{\theta}(t)$ satisfaz as condicóes de regularidade, então, quando $n \longrightarrow \infty$,

$$
\sqrt{n}\left[\hat{s}_{\theta}(t)-s_{\theta}(t)\right] N\left[0, I_{(\theta)}^{-1}\left\{\frac{\partial S_{\theta}(t)}{\partial \theta}\right]^{2}\right]
$$

onde $I(\theta)=\int_{0}^{\infty}\left\{\frac{\partial \log \left(S_{\theta}(u)\right)^{2}}{\partial \theta}\right\} S_{\theta}(u) g(u) d u+$

$+\int_{0}^{\infty}\left\{\frac{\partial \log \left[S_{\theta}(\omega)\right]}{\partial \theta}\right]_{\theta}^{2} \tilde{f}_{\theta}(u)[1-\epsilon(u)] d u$

(2. 35$)$ 
38.

Esses resultados podem ser estendidos para o caso em que o espaco paramétrico tem dimensão $k$, de modo que, neste caso, tem-se:

$$
\sqrt{n}\left[\hat{S}_{\theta}(t)-S_{\theta}(t)\right] \stackrel{D}{\longrightarrow} N\left[0, \partial u I^{-1}(\theta) \partial u\right)
$$

onde dU é um vetor coluna de dimensãa $k$, cujos elementos correspondem à derivada primeira de $S_{\theta}(t)$ com relacão a $\theta_{i}$, $i=1, \ldots, k \in I(\theta) \doteq$ a matriz de informação de Fisher, definida apropriadamente para observacões sujeitas a censuras, cujo elemento $\mathrm{C} i, j \mathrm{j}$ é dado por:

$$
E\left[J\left(\theta_{i}, \theta_{i}\right)\right]=E\left[\frac{\partial \ell_{i}^{\delta} c_{\left.y_{i}, \theta\right)}}{\partial \theta_{i}} \frac{\left.\partial \ell_{i}^{\delta_{i}} c y_{i}, \theta\right)}{\partial \theta_{j}}\right]
$$

Dentre os model os paramétricos podemos citar:

\subsubsection{Modelo exponencial}

Uma variável aleatória $T$ tem distribuição exponencial com parâmetro $\lambda$ se a função densidade é dada por:

$$
f(t)=\lambda e^{-\lambda t}, \lambda>0, t>0 .
$$


39.

A média e variância de $T$ são respectivamente dadas por: $\quad E(T)=1 / \lambda, V(T)=1 / \lambda^{2}$.

Segundo MILLER (1981), LAMLESS (1982) e LEE (1980), a funcão de sobrevi vência, $S(t), e$ a funcão de risco, h(t), da distribuição exponencial são dadas, respectivamente, por:

$$
S(t)=P[I>t]=\int_{t}^{\infty} f(x) d x=\int_{t}^{\infty} \lambda e^{-\lambda x} d x=
$$

$$
\left.=-e^{-\lambda x}\right]_{1}^{\infty}=e^{-\lambda t}
$$

(2. 36)

$$
h(t)=\frac{f(t)}{S(t)}=\frac{\lambda e^{-\lambda_{t}}}{e^{-\lambda t}}=\lambda
$$

(2. 37)

Nota-se que uma das características da distribuicão exponencial é a função de risco constante, isto é, depende apenas do valor de $\lambda$ e não do tempo.

$$
\text { Fazendo uma reparametrizacão }\left[\theta=\frac{1}{\lambda}\right] \text { na }
$$

distribuicão exponencial abtem-se:

$$
f(t)=\frac{1}{\theta} e^{-t / \theta}, \theta>0, t>0
$$

$$
E(T)=\theta, \quad V C T)=\theta^{2}
$$




$$
h(t)=\frac{1}{\theta} e S(t)=e^{-t \cdot \theta} .
$$

Para estimar $\theta$, utiliza-se o método da máxíma verossimi I hanca CM. V.).

Segundo BONFARINE et ali $(1991)$ no caso em que a amostra dos tempos de vida não apresenta observacóos censuradas, têm-se que a função de verossimilhança, baseado nos tempos $T_{1}, \ldots, T_{n}$, é dada por:

$$
L(\theta)=\frac{1}{\theta^{n}} e^{-\frac{1}{\theta} \sum_{i=1}^{n} t_{i}}
$$

Quando a amostra apresenta censura tipo II, isto é, o tempo de censura é $i$ xo supondo a ocorrência de $r$ falhas, a funç̃o de verossimilhança fica:

$$
L(\theta)=\frac{1}{\theta^{n}} e^{-v / \theta}
$$

onde a estatistica $V=\sum_{i=1}^{r}(i)+(n-r) t_{(r)} \dot{\theta}$ conhecida como o tempo total do ensaio e $t_{(x)}$ é o tempo de ocorrência da r-ésima falha.

Se a censura for do tipo I ou aleatória, inferências exatas são mais complexas. Discutir-se-á apenas métodos aproximados baseados nas propriedades dos 
estimadores de máxima verossimilhança. Nestes casos a funça de verossimilhança pode ser escrita como:

$$
L(\theta)=\frac{1}{\theta^{r}} e^{-v / \theta}
$$

onde $r=\sum_{i=1}^{n} \delta_{i} \Leftrightarrow$ oúmero de falhas e $V=\sum_{i=1}^{n} y_{i}=\sum_{i \in D} T_{i}+\underset{i \varepsilon c}{\sum} L_{i}$,

onde $D$ representa a conjunto dos individuos com tempos de vida observados e C denota o conjunto dos individuos com tempo de vida censurados.

Para este último caso temos que o estimador de M.V. de $\theta$ édado por:

$$
\hat{\theta}=\frac{V}{r}
$$

e a função de informação e dada por:

$$
J(\theta)=\frac{\partial^{2} \log [L(\theta)]}{\partial \theta^{2}}=\frac{r}{\theta^{2}}-\frac{2 V}{\theta^{9}}
$$

Sendo os tempos de censura $L_{i}$ fixos $e$ conhecidos para todos os elementos da amostra, temos que: 
i) $E\left[Y_{i} \mid \delta_{i}=0\right]=L_{i}$

ii) $E\left[Y_{i} \mid \delta_{i}=1\right]=\theta-\frac{L_{i} e^{-L_{i} / \theta}}{1-e^{-L_{i} / \theta}}$

$i i() E(r)=\sum_{i=1}^{n}\left(1-e^{-L_{i} / \theta}\right)$

Prova:

Sabendo-se que $f_{y_{i}}\left(y_{i}\right)= \begin{cases}\frac{1}{\theta} e^{-y_{i}-\theta}, y_{i}<L_{i} \\ e^{-L_{i}-\theta}, y_{i}=L_{i} \\ 0, & , y_{i}>L_{i}\end{cases}$

tem-se que:

$$
\text { i) } P\left(Y_{i}=L_{i} \mid \Delta_{i}=0\right)=\frac{P\left(Y_{i}=L_{i}, \Delta_{i}=0\right]}{P\left(\Delta_{i}=0\right)}=\frac{S\left[L_{i}\right]}{s\left[L_{i}\right]}=1
$$


pois, se:

$$
\Delta_{i}=\left\{\begin{array}{l}
1 \text { se } T_{i} \leq L_{i} \\
0 \text { se } T_{i}>L_{i}
\end{array}\right.
$$

então, $\sigma_{i}$ tem distribuicão binomial com parâmetro 1 e $P\left[T_{i}<L_{i}\right]$, ou seja, $\delta_{i} \cap b\left[1,1-S C L_{i}>\right)$. Portanto,

$$
E\left[Y_{i} \mid \Delta_{i}=0\right]=L_{i} P\left(Y_{i}=L_{i} \mid \Delta_{i}=0\right)=L_{i}
$$

pois para $L_{i}>T_{i}$ a densidade nula.

$$
\begin{aligned}
& \text { ii) } P\left[Y_{i}=T_{i} \mid \Delta_{i}=1\right]=\frac{P\left(Y_{i}=T_{i}, \Delta_{i}=1\right)}{P\left[\Delta_{i}=1\right]}=\frac{\frac{1}{\theta} e^{-y_{i} / \theta}}{1-S\left[L_{i}\right]}= \\
& =\frac{1}{\theta} e^{-y_{i} / \theta} \\
& \frac{1-e^{-L / \theta}}{-L_{i} / \theta}
\end{aligned}
$$


44.

$$
E\left(T_{i} \mid \Delta_{i}=1\right)=\frac{1}{\theta} \int_{0}^{L_{i}} \frac{t e^{-i / \theta}}{1-e^{-L_{i}-\theta}} d t=
$$
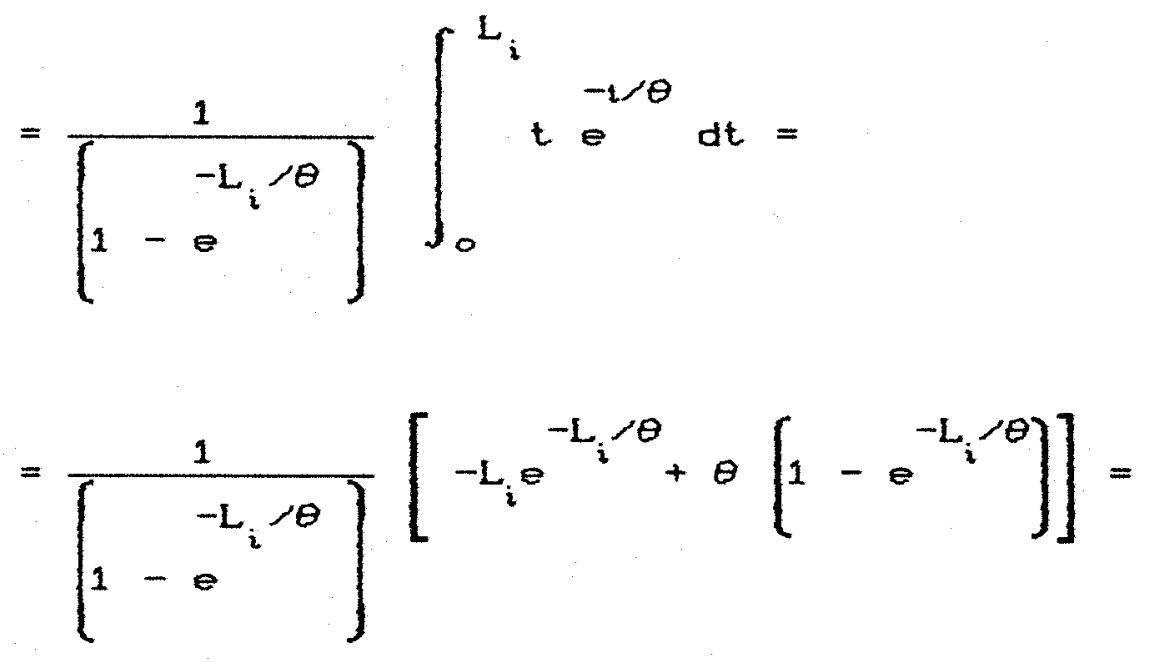

$$
=\theta-\frac{L_{i} e^{-L_{i} / \theta}}{1-e^{-L_{i} / \theta}}
$$

$$
\text { Portanto, } E\left[y_{i} \mid \Delta_{i}=1\right)=\theta-\frac{L_{i} e^{-L_{i} / \theta}}{1-e^{-L_{i} / \theta}}
$$


45.

ii $E(r)=E\left[\sum_{i=1}^{n} \Delta_{i}\right]=\sum_{i=1}^{n} E\left[\Delta_{i}\right]$

Como $\left.\Delta_{i} \cap b\left[1,1-S C L_{i}\right)\right]$

$E\left[\Delta_{i}\right]=1 \cdot P\left[\Delta_{i}=1\right]+O P\left(\Delta_{i}=0\right]=$

$=1\left[1-S\left[L_{i}\right]\right]=1-e^{-L_{i} / \theta}$

Portanto, $\quad E(r)=\sum_{i=1}^{n}\left[1-e^{-L_{i} / \theta}\right]$

De acordo com estes mesmos autores, para se fazerem inferências sobre o parâmetro, pode-se usar o fato de que:

$$
\frac{\hat{\theta}-\theta}{I(\hat{\theta})^{-1 / 2}} \sim N(0,1) \text {, para } n \longrightarrow \infty
$$

onde $\quad I(\hat{\theta})=-\frac{1}{\hat{\theta}^{2}} \Sigma\left(1-e^{-L_{i} \hat{\theta}}\right]$.

No caso em que os $L_{i}$ não são conhecidos para todo elemento da amostra, ou quando a censura é do tipo aleatórto, não é possivel usar a fórmula (2. 43). Contudo, sendo a 
46.

$$
I_{0}=-\left.\frac{\partial^{2} \log (L(\theta))}{\partial \theta^{2}}\right|_{\hat{\theta}}=\frac{r}{\hat{\theta}^{2}}
$$

a informacão obser vada, temos que:

$$
\frac{\hat{\theta}-\theta}{J_{0}^{-1 / 2}} \sim N(0,1), \text { quando } n \rightarrow \infty
$$

As inferências que seguem da fórmula (2. 43) e da fórmula (2. 44) são praticamente as mesmas.

$$
\text { Para testar } H_{0}: \theta=\theta_{0} \text {, pode-se utilizar }
$$

também a estatistica.

$$
\left.\hat{1}=2\left\{\log [\operatorname{L(\theta )}]-\log \left(\operatorname{L(\theta } \theta_{0}\right)\right]\right\}
$$

que é usualmente conhecida por estatística do teste da razão de verossimilhanca. Pode-se mostrar que a estatistica tem distribuição assintótica quiquadrado com 1 grau de Liberdade.

\subsubsection{Modelo de Meibull}

Neste modelo será considerada apenas a situacão usual, que leva a uma amostra com censuras aleatórias ou censuras do tipo $I$, onde $T_{i}$ e $L_{i}$ representam, respectivamente, as tempos de vida de censura para o 
$i$-ésimo indi víduo, $i=1, \ldots, n$.

A funcão densidade de probabilidade desta distribuição é dada por:

$$
f(t)=\lambda \beta(\lambda t)^{\beta-1} e^{-\left(\lambda_{t}\right)^{\beta}}, t>0
$$

onde $\beta, \lambda>0$ são os parâmetros da distribuicão.

Para este modelo, segundo MILLER (1981), LEE (1980) e LAKLESS (1982), a funcão de sobrevivência, SCt), e a funcão de $r i s c o, h(t)$, são dadas, respectivamente, por:

$$
S(t)=P(T>t)=e^{-(\lambda t)^{\beta}}
$$

e

$$
h(t)=\lambda \beta(\lambda t)^{\beta-1}
$$

Em BONFARINE et ali $i$ (1991) tem-se que:

$$
E\left(T^{2}\right)=\frac{\Gamma(1+2 / \beta)}{\lambda^{2}}
$$

onde $\Gamma(x)=\int_{0}^{\infty} u^{k-1} e^{-u} d u, u>0$, é conheci da como $f$ uncão gama. Daí, 


$$
E(T)=\frac{\Gamma(1+1 / \beta)}{\lambda} \otimes V(T)=\frac{\Gamma(1+2 / \beta)-\Gamma(1+1 \beta \beta)}{\lambda^{2}}
$$

A distribuicão de Weibull é muito utilizada em problemas de análise de dados de sobrevivência, haja vista a grande quantidade de formas que a funcão de risco $h(t)$ pode assumir.

Para se estimarem os parametros deste modelo utilizou-se o método da máxima verossimil hanca.

No caso de censuras do tipo I, ou censuras aleatórias, a função de verossimilhanca é dada por:

$$
\begin{aligned}
& L(\lambda, \beta)=\prod_{i=1}^{n}\left[f_{\theta}\left(t_{i}\right)\right]^{\delta}\left[s_{\theta}\left(t_{i}\right]^{1-\delta_{i}}=\right. \\
& =\left(\lambda^{\beta} \beta\right)_{D}^{n} t_{i}^{\beta-1} e^{-\lambda}\left[\sum_{D}^{\Sigma} t_{i}+\underset{c}{\Sigma} L_{i}\right],
\end{aligned}
$$

onde $D$ é $o$ conjunto de individuos com tempo de vida observado, $C$ o conjunto de individuos con tempo de vida censurado e $r=\sum_{i=1}^{n} \delta_{i}$.

Derivando-se o logaritmo da função de verossimilhanca em relacão a $\lambda$ $\beta$, chegou-se às equacóos de verossimil hança, que são dadas por: 


$$
\frac{\sum_{i=1}^{n} t_{i}^{\hat{\beta}} \log \left(t_{i}\right)}{\sum_{i=1}^{n} t_{i}^{\hat{\beta}}}-\frac{1}{\hat{\beta}}-\frac{1}{r} \sum_{i \in D}^{\sum} \log _{i}\left(t_{i}\right)=0
$$

e

$$
\hat{\lambda}=\left[\frac{1}{r} \sum_{i=1}^{n} t_{i}^{\hat{\beta}}\right)^{1 \hat{\beta}}
$$

Estas equaçóes não apresentam solução analitica, tendo que ser utilizado um método iterativo, como por exemplo, o método de Newton-Raphson, para se encontrarem $\hat{\lambda} \otimes \hat{\beta}$.

Na identificação de um modelo apropriado para se analisarem dados de sobrevivência com censura, é usual considerarem-se procedimentos gráficos envolvendo a funcão de sobrevivencia. Em BONFARINE et ali $(1991)$, tem-se que o modelo exponencial será apropriado para os dados censurados, quando o gráfico de $-10 g\left(S_{k m}(t)\right]$ versus $t$ for aproximadamente 1 inear, passando pela origem, e tem-se que o modelo Meibull será apropriado para um conjunto de dados censurados quando o gráfico de

$\log \left[-\log \left[\hat{S}_{k m}(t)\right]\right]$ versus $\log (t)$ for aproximadamente linear apenas. 
50.

Segundo estes mesmos autores, podem-se também utilizar a estatistica da razão de verossimilhanca. Sob $H_{0}$, - estimador de máxima verossimilhanca de $\beta$ é dado por $\hat{\beta}=\beta_{0}$. Por outro lado, 0 estimador de máxima verassimilhanca de $\lambda$ é obtido por:

$$
\hat{\lambda}=\left[\frac{\sum_{i=1}^{n} t_{i}^{\beta}}{r}\right]^{1 / \beta_{0}}
$$

A estatística da razão de verossimilhança é então dada por:

$$
\left.\hat{n}_{2}=-2 \log \left(\operatorname{L}\left(\hat{\lambda}, \beta_{0}\right)\right]+2 \log [\operatorname{LC} \hat{\lambda}, \hat{\beta})\right]
$$

onde $\hat{\lambda}$ e $\hat{\beta}$ são os estimadores de máxima verossimilhança no modelo sem restricão obtidos pela resol ução da equação dada em (2. 49), e pode-se mostrar que a estatística $\hat{A}_{z}$ tem distribuicão assintótica de quiquadrado com 1 grau de 1 i ber dade.

2.10. Testes parametricos para a comparaço de duas distribuiçôs

Após a identificação de um modelo paramétrico para os conjuntos de dados e a estimacão de suas respectivas funcôes de sobrevi vência, é comum haver interesse na 
comparacão destas funções, pois na prática o pesquisador está interessado em comparar os tratamentos dois a dois.

Em LEE (1980), tem-se os seguintes métodos para comparar duas distribuicốes de sobrevi vência:

\title{
2.10.1. Comparaçåo de duas distribuiçós exponenciais
}

\begin{abstract}
Supondo-se que duas distribuicôes de sobrevi vência sigam o modelo exponencial com parâmetros $\lambda_{1} \theta$ $\lambda_{2}$, respectivamente. Dais testes podem comparar: as distribuicóes quando nenhum grupo tem mais do que um parâmetro: o teste da razăo de verossimilhança e um teste F, sugerido por CoX (1953).
\end{abstract}

\subsubsection{Teste da razáo de verossimilhança}

Supondo-se que se tenham $n_{1} e n_{2}$ individuos nos grupos 1 e 2 , respectivamente, $x_{1}, \ldots, x_{r}$ não censurados $e x_{r_{1}+1}, \ldots, x_{n_{1}}$ censurados no grupo 1 , e $\mathrm{Y}_{1}, \ldots, \mathrm{Y}_{r_{2}}$ não censurados $e \mathrm{Y}_{r_{2}^{+1}}^{Y_{1}} \ldots, \mathrm{Y}_{r_{2}}$ censurados no grupo 2. Desta maneira, no grupo 1 , há $r_{1}$ observacóes não censuradas e $\left(n_{1}-r_{1}\right)$ observacões censuradas. No grupo 2 , há $r_{2}$ observacões năo censuradas e $\left.\mathrm{Cn}_{2}-r_{2}\right)$ observacões censuradas. Se é conhecido que o tempo de sobrevívência do 
52.

grupo 1 e do grupo 2 segue uma distribuicão exponencial com parâmetro $\lambda_{1} e \lambda_{2}$, respectivamente, então testar a igualdade das duas distribuicões exponenciais é equi valente a testar a hipótese $H_{0}: \lambda_{1}=\lambda_{2}$, isto porque as duas distribuicốes exponenciais são caracterizadas pelos dois parâmetros $\lambda_{1}$ $\lambda_{2}$. Deste modo, a hipótese nul a é:

$$
H_{0}: \lambda_{1}=\lambda_{2}=\lambda \text { vs } H_{1}: \lambda_{1} \neq \lambda_{2}
$$

A estatística para o teste da razão de verossimi l hança será:

$$
\Lambda=\frac{\operatorname{LC} \hat{\lambda}, \hat{\lambda})}{\operatorname{LC} \hat{\lambda}_{1}, \hat{\lambda}_{2}{ }^{2}}
$$

onde $L(\hat{\lambda}, \hat{\lambda})$ é a funcão de verossimilhanca conjunta, calculada sob $H_{0}$ Sob $H_{1}, \quad \hat{\lambda}_{1}$ e $\hat{\lambda}_{2}$ são estimativas de máxima verossimilhança de $\lambda_{1} e \lambda_{2}$, dos grupos $1 e z$, respectivamente, que são dadas por:

$$
\hat{\lambda}_{1}=\frac{r_{1}}{\sum_{i=1}^{r_{1}} x_{i}+\sum_{i=r_{1}+1}^{n_{1}} x_{i}^{\prime}}
$$




$$
\begin{aligned}
& \hat{\lambda}_{2}=\frac{r_{2}}{r_{2}} \\
& \sum_{i=1} y_{i}+\sum_{i=r_{2}+1} y_{i}
\end{aligned}
$$

Sob $H_{0}, \hat{\lambda}$ é o estimador de M.V. obtido na amostra combinada e dado por:

$$
\hat{\lambda}=\frac{r_{1}+r_{2}}{\sum_{i=1}^{r_{1}} x_{i}+\sum_{i=r_{1}+1}^{n_{1}} x_{i}+\sum_{i=1}^{r_{2}} y_{i}+\sum_{i=r_{2}+1}^{r_{2}} y_{i}}
$$

Sabendo-se que $-2 \log \wedge$ tem distribuiçăo assintótica de quiquadrado com um grau de liberdade sob $H_{0}$ " a hipotese $H_{0}$ e rejeitada se $-2 \log \wedge$ exceder $x_{1, a}^{2}$ para distribuiça de $\chi^{2} \operatorname{com} 19.1$. e um nivel de significancia $a$. o teste da razão de verossimilhança é primariamente bilateral e e dificil aplicálo em teste unilateral.

\subsubsection{Teste F de cox}

Quando pode ser assumido que os tempos de falhas são distribuldos exponencialmente em ambos os grupos 
54.

de tratamentos, um teste F, sugerido por CoX (1953), pode ser usado para testar diferentes tratamentos se a censura estiver ou não presente.

Suponha-se que a hipótese a ser testada seja $H_{0}: \lambda_{1}=\lambda_{2}$ contra a hipótese alternativa unilateral $H_{1}: \lambda_{1}<\lambda_{2}$ Cou $H_{2}: \lambda_{1}>\lambda_{2}$, ou bilateral $H_{3}: \lambda_{1} \neq \lambda_{2}$ Um teste eficiente para estas hipóteses é tomar $\bar{t}_{1}, \bar{t}_{2}$ como tendo uma distribuicăo $F$ com $\operatorname{car}_{1}$, $\left.2 \mathrm{ar}_{2}\right)$ graus de liberdade, onde:

$$
\begin{aligned}
& \bar{t}_{1}=\frac{\sum_{i=1}^{r_{1} x_{i}+\sum_{i=1+r_{1}}^{n_{1}} x_{i}^{\prime}}}{r_{1}} \\
& \bar{t}_{2}=\frac{\sum_{i=1}^{r_{2} y_{i}+\sum_{i=1+r_{2}}^{n_{2}} y_{i}^{\prime}}}{r_{2}}
\end{aligned}
$$

Os procedimentos do teste serão:

(1) para $H_{1}$, rejeita-se $H_{0}$ se $\bar{t}_{1}, \bar{t}_{2}>\mathrm{F}_{\mathrm{C2r}_{1}, 2 r_{2}, \infty}$;

(2) para $H_{2}$, rejeita-se $H_{0}$ se $\bar{t}_{1}, \bar{t}_{2}<F_{C_{2 r_{1}, 2 x}, 1-\infty}$;

(3) para $H_{3}$, rejeita-se $H_{0}$ se $\bar{t}_{1},-\bar{t}_{2}<F_{\left(2 r_{1}, 2 r_{2}, 1-a r\right)}$ ou

$\bar{t}_{1} / \bar{t}_{2}>F_{\left(2 r_{1}, 2 r_{2}, a / z\right)}$ onde a é o nível de significância. 
55.

\subsubsection{Comparaçăo de duas Distribuiçŏes Weibull}

Segundo LEE (1980), o tempo de sobrevi vência I tem distribuicão Weibull com parâmetro $\gamma$, então $T^{\gamma}$ tem uma distribuição exponencial. Assim, quando as observacões em cada amostra sofrem transformacŏes pode-se utilizar o teste F de Cox para comparar as 2 amostras.

Assuma-se que amostras aleatórias independentes de tamanhos iguais $\left.C_{1}=n_{2}=n\right)$ são obtidas de uma distribuicão Heibull $f_{1}(t)$ e $f_{2}(t)$ onde:

$$
\begin{array}{r}
f_{i}(t)=\lambda_{i} \gamma_{i}\left(\lambda_{i} t\right)^{\gamma_{i}^{-1}} \exp \left[-\left(\lambda_{i} t\right)^{\gamma_{i}}\right], i=1,2 . \quad(2.56) \\
\text { Para se testar a igualdade de } f_{i}(t) \text { ef }(t) e
\end{array}
$$
suficiente testar-se $\gamma_{1}=\gamma_{2}$ e $\lambda_{1}=\lambda_{2}$. Se a hipótese $\gamma_{1}=\gamma_{2}$ for rejeitada não haverá necessidade de se testar $\lambda_{1}=\lambda_{2}$. Mas se $\gamma_{1}=\gamma_{2}$ não for rejeitada, então haverá necessidade de se testar $\lambda_{1}=\lambda_{2}$.

Para se testar $\gamma_{1}=\gamma_{2}$ usam-se as propriedades do estimador de máxima verossimilhanca $\hat{\gamma}$. para se testar $H_{0}: \gamma_{1}=\gamma_{2}$ contra $H_{1}: \gamma_{1}>\gamma_{2}$, usa-se:

$\frac{\frac{\hat{r}_{1}}{r_{1}}}{\frac{\hat{r}_{2}}{r_{1}}}=\frac{\hat{r}_{1}}{\hat{r}_{2}}$ sob $H_{0}$ os pontos porcentuais de $r_{1} \gamma_{2}$ são dados pela tabela encontrada em THOMAN \& BAIN (1969). 
56.

2.11. Eficiencia assintótica relativa dos estimadores da funça de sobrevi vencia

LEITE \& SINGER (1990) dizem que muitos estimadores usualmente empregados em análises estatisticas são consistentes têm distribuição assintoticamente normal. Então, para se escolher um estimador dentre um conjunto de, estimadores precisa-se de algum critério adiclonal.

$\left\{\hat{\theta}_{n}^{(1)}\right\}_{n \geq 1}=\left\{\hat{\theta}_{n}^{(2)}\right\}_{n \geq 1}$ de estimadores, tais que:

$$
\sqrt{n}\left[\hat{\theta}_{n}^{(1)}-\theta\right] \stackrel{D}{\longrightarrow} N\left(0, \sigma_{1}^{2}\right) \quad \theta
$$$$
\sqrt{n}\left[\hat{\theta}_{n}^{(2)}-\theta\right] \stackrel{D}{\longrightarrow} N\left(0, \alpha_{2}^{2}\right]
$$

Podemos utilizar as variâncias assintóticas $\alpha_{1}^{2} e \alpha_{2}^{2}$ para definir a eficiência assintótica relativa (EAR) dé $\hat{\theta}_{n}^{(z)}$ com respeito a $\hat{\theta}_{n}^{(1)}$, como:

$$
\operatorname{EAR}\left[\hat{\theta}_{n}^{(2)} \hat{\theta}_{n}^{(1)}\right]=\frac{\alpha_{1}^{2}}{\alpha_{2}^{2}}
$$


Obviamente, se $\operatorname{EAR}\left[\hat{\theta}_{n}^{(2)} \hat{\theta}_{n}^{(1)}\right]<1, \hat{\theta}_{n}^{(1)} \dot{\theta}$ mais eficiente que $\hat{\theta}_{n}^{(2)}$.

Segundo BONFARINE et alii (1991), para o caso sem censura é possivel obterem-se expressães analíticas para a eficiência assintótica. Quando a amostra contém observacões censuradas ou tem poucas observacốes, algumas indicacôes sobre o comportamento assintótico da eficiência são obtidos por simulação.

Como foi visto anteriormente, podem-se utilizar técnicas paramétricas e não-paramétricas para análise de dados de sobrevivêneia. As técnicas nãoparamétricas, segundo estes mesmos autores, são usadas quando existem dificuldades na identificação de um modelo paramétrico para os dados em estudo. Há estudos também em que na maioria dos casos as técnicas paramétricas são mais eficientes que as não-paramétricas.

MILLER (1983), utilizando-se de dados simulados, compara a eficiência assintótica do estimador de Kaplan-Meier com um estimador paramétrico da funcão de sobrevivência, variando as proporcóes de censura e de sobrevi vência. 
58.

\section{METODOLOGIA}

Os métodos clássicos para esti mação da funcăo de sobrevi vência são muito utilizados na medicina com dados clínicos e na engenharia com dados de falhas de componentes físicos (por exemplo, durabilidade de lâmpadas). Já na área agrária os experimentos não são conduzidos para serem analisados como dados de sobrevi vência. Acredita-se que seja por falta de informąão dos pesquisadores nesta linha. Devido a este fato achou-se por bem simular um conjunto de dados para mostrar a aplicação e utilidade desses métodos.

Para simulação deste conjunto de dados foi utilizado o programa estatistico SAS. Geraram-se duas amostras de sessenta dados da distribuição exponencial, cada uma, sendo que cinqüenta dados são referentes ao tempo de falha os 10 restantes são referentes ao tempo de censura. A amostra 1 foi gerada com semente 34 , com parâmetro $\lambda=2$ para tempo de falha, e parâmetro $\lambda=1$ para tempo de censura. A amostra 2 foi gerada com semente 50 e parâmetro $\lambda=4$ para tempo de falha, e parâmetro $\lambda=2$ para tempo de censura. Tanto os dados da amostra 1 como da amostra 2 foram multiplicados por 100 aproximados para uma casa decimal, 
59.

assim, a unidade de tempo considerada foi dias.

Após a simulacăo dos dados foi feita uma sequiência de análises utilizando-se métodos de estimacâo da função de sobrevivência. Para execucăo desta sequiencia de análises usou-se o programa "Análise de Sobrevi vência", que utiliza módulos do programa estatístico SOC, o qual está sendo desenvolvido pelos membros do grupo de estudos em Análise de Sobrevi vência e Ensaios Clínicos, coordenado pela professora Cecilia Yuko Wada, do departamento de estatística da UNI CAMP/Campinas.

\subsection{Métodos năo-paramétricos}

Quando se tem um conjunto de dados de sobrevi vência, os primeiros métodos que devem ser utilizados são os não-paramétricos, como tiabela de vida ou Kaplan-Meier. No caso de se ter dados na forma de tempo observado por individuo utiliza-se o método de Kaplan-Meier, mas quando se tem apenas a observação na forma de intervalo de tempo, ou seja, não se sabe exatamente onde o individuo falhou ou foi censurado e sim em que intervalo isto ocorreu, deve-se utilizar tabelas de vida.

No conjunto de dados simulados, foi utilizado - método de Kaplan-Meier, pois sabe-se exatamente quando o individuo falhou ou foi censurado. 
80.

Este método consiste em calcular a probabilidade de sobrevivencia $\hat{S}_{k m}(t)$, para cada um dos tempos observados, usando-se (2. 200 .

O programa utilizado fornece:

i) a probabilidade de falha para cada individuo, calculada segundo $P(T \leq t)=1-\hat{S}_{k m}(t)$,

ii) o desvio padrão dessa probabilidade, que é dado por:

$$
\Delta=\sqrt{\operatorname{var} \hat{S}_{k m}(t)}=\hat{S}_{k m}(t) \sqrt{\sum_{j, t}\left(\frac{d_{j}}{n_{j}\left(n_{j}-d_{j}\right)^{2}}\right)}
$$

onde $d_{j}$ é o número de mortes em $t_{j}$ e $n_{j}$ é o número de indi viduos,

i ii) o tempo médio de vida sua variância, dados por (2. 24) e (2. 25), respecti vamente.

Para a visualização da curva de sobrevi vência foi feito o gráfico do tempo observado $(t)$ vs $S_{k m}(t)$, para cada amostra, utilizando-se os recursos gráficos do programa soc.

3.2. Teste de "Logrank"

Após a obtenção da estimativa da função de sobrevivência pelo método de kaplan-Meier, para cada 
61.

amostra, podem-se utilizar testes não paramétricos para se verificar se há diferença entre as duas amostras quanto a sobrevi vência $\left[H_{0}: S(t)_{1}=S\left(t_{2}\right)\right.$ vs $\left.H_{1}: S(t)_{1} \neq S(t)_{2}\right]$.

Dentre os testes não paramétricos, foi utilizado o teste de "Logrank". Este teste consiste em se calcular uma estimativa do log da funcão de sobrevivência, utilizando-se (2.28) e, posteriormente, calcular-se um escore $\Psi_{i}$ para cada observacão.

Após o cálculo dos escores, calculou-se ar estatistlca do teste $L=S / \sqrt{V}$, a qual tem distribuição assintoticamente normal padrăo sob $H_{0}: S(t)_{1}=S(t)_{2}$ e onde $S$ é a soma dos escores do grupo 2 Camostra 2 e $V$ a variância do teste dado em (2. 29 ).

\subsection{Método parametrico}

Para a estimacão das probabilidades de sobrevi vência pelo método paramétrico é necessário fazer-se a identificação do modelo, por exemplo, através do método gráfico. Se for construido o gráfico de -log(Ŝ́(t)) versus $t$, e se o comportamento do gráfico for uma li near passando pela origem, então tem-se um indicativo de que o modelo dos tempos de sobrevivência é exponencial. Já, se for construído - gráfico de $\log (-\log (\hat{S}(t))$ versus log $t$ e, se o comportamento do gráfico for uma linear, então tem-se um 
62.

indicativo de que o modelo dos tempos de sobrevivência é Weibull.

Muitas vezes, só observando os gráficos, é quase impossivel concluir-se sobre qual o modelo que melhor se ajusta aos dados, sendo necessário um outro método.

Assim, foi considerado, além do método gráfico, um ajuste dos dados à distribuicão do valor extremo, pelo fato de que essa distribuição tem uma forma mais simples que a de Heibull e pela sua facilidade computacional. A distribuição de valor extremo é importante na análise de sobrevivência, pois existe um relacionamento direto con a distribuição de Meibull, isto é, se $T$ tem distribuicão Meibull com funcão densidade de probablidade dada por:

$$
f(t)=\lambda \beta(\lambda t)^{\beta-1} e^{-(\lambda t)^{\beta}}, t>0
$$

onde $\beta, \lambda>0$ são os parâmetros da distribuição, então $X=$ In $(T)$ tem distribuição de valor extremo.

Isso pode ser visto, utilizando-se (3.2) e fazendo-se a transformação $x=\ln (t)$ :

$$
\begin{aligned}
f(x) & =\lambda \beta \lambda^{\beta-1} e^{x(\beta-1)} e^{-\lambda^{\beta} e^{x \beta}} \cdot\left|\frac{d t}{d x}\right|= \\
& =\lambda^{\beta} \beta e^{(x \beta-x)} e^{-\lambda^{\beta} e^{x \beta}} e^{x}=\lambda^{\beta} \beta e^{\left(x \beta \beta-\lambda^{\beta} e^{\beta \beta}\right.},
\end{aligned}
$$


63.

$$
\text { Fazendo-se } \beta=\frac{1}{b} \text { e } \lambda=e^{-\mu}, \text { tem-se: }
$$

$$
\begin{gathered}
f(x)=\frac{1}{b} e^{-\mu / b} e^{x / b} e^{-e^{-\mu / b} e^{x / b}}=\frac{1}{b} e^{\left(\frac{x-\mu}{b} \cdot e^{\frac{x-\mu}{b}}\right)} \\
f(x)=b^{-1} \cdot e^{\left[\frac{x-\mu}{b} \cdot e^{\frac{x-\mu}{b}}\right]}
\end{gathered}
$$

Portanto,

$x$ tem distribuição de valor extremo com $b=1 / \beta=$ $\mu=-\log \lambda$.

Após o ajuste da distribuicão de valor extremo foi feito o teste da razão de verossimilhanca para testar as hipóteses $H_{0}: \beta=1$ vs $H_{1}: \beta \neq 1$ as hipóteses $H_{0}: \lambda=0$ vs $H_{1}: \lambda \neq 0$, pois sabe-se que se $\beta=1$ e $\lambda \neq 0$, 0 modelo pode ser exponencial, que é um caso particular do Weibull.

3. 4. Teste da razăo de verossimilhança para diferença entre duas amostras

Além dos testes não paramétricos foram utilizados testes paramétricos para se testar a igualdade de duas funcões de sobrevi vência. Utilizou-se o teste da razão de verossimilhanca para duas amostras com distribuicão exponencial. 
64.

Para este caso, a hipótese a ser testada é sobre os parâmetros, isto é, testa-se:

$$
H_{0}: \lambda_{1}=\lambda_{2}=\lambda \text { vs } H_{1}: \lambda_{1} \neq \lambda_{2}
$$

pois se $H_{\circ}$ for aceita, pode-se supor que as distribuicóes são iguais.

o procedimento para este teste, como já visto, consiste em estimar $\lambda_{1}, \lambda_{2}$ e $\lambda$ dados em (2.51), (2.52) e (2.53), respectivamente, e construir a razăo de verossimilhanca $\Lambda$ dada em (2.50), usando o fato que - 21 log $\Lambda$ tem distribuição assintoticamente $\chi_{1}^{2}$ estabeleceu-se a regra de decisão:

$$
\begin{cases}-2 \log \Lambda>x_{1, \alpha}^{2} & \text { rejeita-se } H_{0} \\ \text { caso contrário } & \text { não rejeita-se } H_{0}\end{cases}
$$

onde a é um nível de significância apropriado.

\subsection{Eficiencia assintótica relativa}

Para se calcular a eficiência do estimador produto 1 imite fou estimador de Kaplan-Meier), com relacão ao estimador de máxima verossimilhança da distribuicão exponencial $\left(\hat{S}_{\theta}(t)\right)$, utilizouse a eficiencia assintótica relativa, ou seja, calculou-se:

$$
E_{A}(t)=\frac{\operatorname{var} A\left[\hat{S}_{\theta}(t)\right]}{\operatorname{Var}_{A}\left[\hat{S}_{k m}(t)\right]}
$$


65.

onde:

$$
\begin{aligned}
\operatorname{Var}_{A}\left[\hat{S}_{k m}(t)\right] & =\frac{1}{n}\left[S_{\theta}(t)\right]_{0}^{2} \int_{0}^{t} \frac{f_{\theta}(u)}{[1-(x) u]\left(S_{\theta}(u)\right]^{2}} d u= \\
& =\frac{1}{n} e^{-2 \theta t} \int_{0}^{1} \frac{\theta e^{-\theta u}}{e^{-\mu u} e^{-2 \theta u}} d u= \\
& =\frac{1}{n} e^{-2 \theta t}\left[e^{(\theta+\mu) t}-1\right) \frac{\theta}{\theta+\mu}
\end{aligned}
$$

pois $\quad S_{\theta}(t)=e^{-\theta t}$ e $1-\alpha(t)=e^{-\mu t}, e$

$$
\operatorname{Var}\left[\hat{S_{\theta}}(t)\right]=\frac{1}{n} I^{-1}(\theta)\left[\frac{\partial \hat{S}_{\theta}(t)}{\partial \theta}\right]=\frac{1}{n} \theta t^{2}\left(\theta+\mu e^{-2 \theta t}\right.
$$

pois,

$I(\theta)=-E\left[\frac{\partial^{2} \log \left(f_{\theta}(t)\right)}{\partial \theta^{2}}\right]=\frac{1}{(\theta+\mu) \theta}$, que é a informação de Fisher para a distribuicão exponencial.

Dai, tem-se que:

$$
E_{A}(t)=\frac{\operatorname{Var} A\left[\hat{S}_{\theta}(t)\right]}{\operatorname{Var}{ }_{A}\left[\hat{S}_{k m}(t)\right]}=\frac{(1+\rho)^{2}(\theta t)^{2}}{e^{(1+\rho) \theta t}-1}
$$

onde $\rho=\mu / \theta$ 
66.

Para se calcular $E_{A}(t)$ em cada tempo observado, considerou-se $\mu=1$ e $\theta=2$ para amostra 1 e $\mu=3 e \theta=4$ para amostra 2 , onde $\mu$ é o parâmetro da distribuicão de censura $e \theta e$ o parâmetro da distribuicão do tempo de vida.

Após o cálculo da eficiencla em cada tempo observado, foi feito um gráfico da eficiência versus tempo, utilizando-se os recursos do programa estatístico SAS. 


\section{RESULTADOS E DISCUSSÃO}

Os conjuntos de dados simulados gerados a partir da distribuicăo exponencial encontram-se nas Tabelas 1 e 2 .

Tabela 1 - Tempo observado nos indi víduos da almostra 1.

\begin{tabular}{cc}
$\begin{array}{c}\text { Tempo observado }\left(y_{i}\right) \\
\text { (em dias) }\end{array}$ & Indicador de Censura $\left(\delta_{i}\right)^{-1}$ \\
\hline 02,1 & 1 \\
0,8 & 1 \\
26,0 & 1 \\
10,0 & 1 \\
54,7 & 1 \\
2,3 & 1 \\
38,7 & 1 \\
127,9 & 1 \\
18,3 & 1 \\
68,7 & 1 \\
7,7 & 1 \\
10,4 & 1 \\
208,6 & 1 \\
62,9 & 1 \\
30,9 & 1 \\
112,9 & 1 \\
65,7 & 1 \\
39,1 & 1 \\
78,0 & 1 \\
17,7 & 1 \\
45,8 & 1 \\
169,1 & 1 \\
0,5 & 1 \\
&
\end{tabular}


68.

Tabela 1 - Tempo observado nos individuos da amostra 1 (conti nuação).

\begin{tabular}{|c|c|c|c|}
\hline $\begin{array}{l}\text { Tempo observado }\left(y_{i}\right) \\
\text { (em dias) }\end{array}$ & Indicador de & Censura & $\left(\delta_{i}\right)$ \\
\hline 13,3 & 1 & & \\
\hline 86.6 & 1 & & \\
\hline 15,8 & 1 & & \\
\hline 27,8 & 1 & & \\
\hline 31,3 & 1 & & \\
\hline 10,7 & 1 & & \\
\hline 10,0 & 1 & & \\
\hline 13,4 & 1 & & \\
\hline 74,7 & 1 & & \\
\hline 20,7 & 1 & & \\
\hline 26,4 & 1 & & \\
\hline 151,4 & 1 & & \\
\hline 112,4 & 1 & & \\
\hline 61,0 & 1 & & 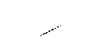 \\
\hline 138,6 & 1 & & \\
\hline 113,2 & 1 & & \\
\hline 16,8 & 1 & & \\
\hline$\quad 20,6$ & 1 & & \\
\hline 24,1 & 1 & & \\
\hline 92,0 & 1 & & \\
\hline 12,6 & 1 & & \\
\hline 24,2 & 1 & & \\
\hline 54,1 & 1 & & \\
\hline 18,9 & 1 & & \\
\hline 24,7 & 1 & & \\
\hline 47,7 & 1 & & \\
\hline 15,8 & 1 & & \\
\hline 124,2 & 0 & & \\
\hline 1,7 & 0 & & \\
\hline 52,1 & 0 & & \\
\hline 19,9 & 0 & & \\
\hline 100,5 & 0 & & \\
\hline 4,6 & 0 & & \\
\hline 77,4 & 0 & & \\
\hline 255,7 & 0 & & \\
\hline $3 B, 7$ & 0 & & \\
\hline 133,5 & 0 & & \\
\hline
\end{tabular}


69.

Tabela 2 - Tempo observado nos indivíduos da amostra 2.

\begin{tabular}{|c|c|c|c|c|c|}
\hline $\begin{array}{r}\text { Tempo } \\
\mathrm{C}\end{array}$ & $\begin{array}{l}\text { Obser vado }\left(y_{i}\right) \\
\text { m dias) }\end{array}$ & Indicador & de & Censura & $\left(\theta_{i}\right)$ \\
\hline & 34,8 & & 1 & & \\
\hline & 17,1 & & 1 & & \\
\hline & 0,2 & & 1 & & \\
\hline & 0,8 & & 1 & & \\
\hline & 63,1 & & 1 & & \\
\hline & 19,2 & & 1 & & \\
\hline & 47,6 & & 1 & & \\
\hline & 13,4 & & 1 & & \\
\hline & 17,8 & & 1 & & \\
\hline & 27,8 & & 1 & & \\
\hline & 0,9 & & 1 & & \\
\hline & 41,0 & & 1 & & \\
\hline & 10,0 & & 1 & & \\
\hline & 25,6 & & 1 & & \\
\hline & 4,0 & & 1 & & \\
\hline & 3,8 & & 1 & & \\
\hline & 11,5 & & 1 & & \\
\hline & 17,5 & & 1 & & \\
\hline & 4,4 & & 1 & & \\
\hline & 28,1 & & 1 & & \\
\hline & 22,2 & & 1 & & \\
\hline & 11,2 & & 1 & & \\
\hline & 1,9 & & 1 & & \\
\hline & 25,4 & & 1 & & \\
\hline & 5,9 & & 1 & & \\
\hline & 34,7 & & 1 & & \\
\hline & 8,0 & & 1 & & \\
\hline & 16,4 & & 1 & & \\
\hline & 51,1 & & 1 & & \\
\hline & 4,0 & & 1 & & \\
\hline & 21,8 & & 1 & & \\
\hline & 27,7 & & 1 & & \\
\hline & 14,5 & & 1 & & \\
\hline & 19,6 & & 1 & & \\
\hline & 18,2 & & 1 & & \\
\hline & 3,7 & & 1 & & \\
\hline & 14,8 & & 1 & & \\
\hline & 11,9 & & 1 & & \\
\hline & 0,6 & & 1 & & \\
\hline & 22,8 & . & 1 & & \\
\hline & 28,0 & & 1 & & \\
\hline & 14,7 & & 1 & & \\
\hline & 1,8 & & 1 & & \\
\hline
\end{tabular}


70.

Tabela 2 - Tempo observado nos individuos da amostra 2 continuação).

\begin{tabular}{cc}
\hline $\begin{array}{c}\text { Tempo observado }\left(y_{i}\right) \\
\text { (em dias) }\end{array}$ & Indicador de Censura $\left(\delta_{i}\right)$ \\
\hline 7,8 & 1 \\
93,7 & 1 \\
20,8 & 1 \\
18,5 & 1 \\
6,2 & 1 \\
14,2 & 1 \\
10,4 & 1 \\
46,5 & 0 \\
22,8 & 0 \\
0,3 & 0 \\
1,0 & 0 \\
84,1 & 0 \\
25,8 & 0 \\
63,5 & 0 \\
17,9 & 0 \\
23,8 & 0 \\
37,1 & 0 \\
\hline
\end{tabular}

Estes dados foram usados nas análises de dados de sobrevi vência, vistas a seguir.

4.1. Metodo de Kaplan-Meier

Os resultados obtidos com a análise de Kaplan-Meier estäo nas Tabelas 3,4 e 3. 
Tabela 3 - Estimativas da probabilidade de sobrevi vência, do desvio padrão da probabilidade de sobrevi vência e da probabilidade de falha de cada individuo da amostra 1 .

\begin{tabular}{ccccc}
\hline Tempo & Indicador & Estimativa da & Estimativa Estimativa \\
Observado & de & Probabilidade & dp & Probab. \\
Cem dias) & Censura & de & Prob. & Falha \\
& & Sobrevivencia & &
\end{tabular}

\begin{tabular}{|c|c|c|c|c|}
\hline 0,5 & 1 & 0,983333 & 0,016527 & 0,016667 \\
\hline 0,8 & 1 & 0,966667 & 0,023174 & 0,033333 \\
\hline 1,7 & 0 & 0,966667 & 0,023174 & 0,033333 \\
\hline 2,3 & 1 & 0,949708 & 0,028301 & 0,050292 \\
\hline 4,5 & 0 & 0,949708 & 0,028301 & 0,050292 \\
\hline 7,7 & 1 & 0,932440 & 0,032631 & 0,067580 \\
\hline 9,9 & 1 & 0,915173 & 0.036309 & 0,084827 \\
\hline 10,0 & 1 & 0,897905 & 0,039517 & 0,102095 \\
\hline 10,4 & 1 & 0,880638 & 0,042362 & 0,119362 \\
\hline 10,7 & 1 & 0,863371 & 0,044913 & 0,136629 \\
\hline 12,8 & 1 & 0,846103 & 0,047218 & 0,153897 \\
\hline 13,3 & 1 & 0.828836 & 0,049311 & 0,171104 \\
\hline 13,4 & 1 & 0,811568 & 0,051217 & 0,188432 \\
\hline 15,8 & 1 & 0,794301 & 0,052959 & 0,205690 \\
\hline 15,8 & 1 & 0,777033 & 0,054550 & 0,222967 \\
\hline 16,8 & 1 & 0,759766 & 0,056004 & 0,240234 \\
\hline 17,7 & 1 & 0,742499 & 0,057331 & 0,257501 \\
\hline 18,3 & 1 & 0,725231 & 0,058541 & 0,274709 \\
\hline 18,9 & 1 & 0,707964 & 0,059639 & 0,292036 \\
\hline 19,9 & 0 & 0,707964 & 0,059839 & 0,292036 \\
\hline 20,6 & 1 & 0,690265 & 0,060718 & 0,309735 \\
\hline 20,7 & 1 & 0,872566 & 0,061686 & 0,327434 \\
\hline 24,1 & 1 & 0,654867 & 0,062551 & 0,345133 \\
\hline 24,2 & $\overline{1}$ & 0,637167 & 0,063315 & 0,302833 \\
\hline 24,7 & 1 & 0,619468 & 0,063982 & 0,380532 \\
\hline 26,0 & 1 & 0,801789 & 0,064556 & 0,398231 \\
\hline 26,4 & 1 & 0,584070 & 0,005038 & 0,415930 \\
\hline 27,8 & 1 & 0,566371 & 0,065431 & 0,433629 \\
\hline 30,9 & 1 & 0,548672 & 0,065737 & 0,451328 \\
\hline 31,3 & 0 & 0,548672 & 0,065737 & 0,451328 \\
\hline 36,7 & 1 & 0,530383 & 0,066040 & 0,469617 \\
\hline 38,7 & 1 & 0,512094 & 0,066247 & 0,487906 \\
\hline 39,1 & 1 & 0,493805 & 0,068358 & 0,506195 \\
\hline 45,8 & 1 & $0,47551 \mathrm{~B}$ & 0,068373 & 0,524484 \\
\hline 47,7 & 0 & 0,475516 & 0,066373 & 0.524484 \\
\hline 54,1 & 1 & 0,456495 & 0,066387 & 0,543505 \\
\hline 54,1 & 1 & 0,437474 & 0,068290 & 0,562526 \\
\hline
\end{tabular}


Tabela 3 - Estimativas da probabilidade de sobrevi vência, do desvio padrão da probabili dade de sobrevi vência da probabilidado do falha do cada indivíduo da amostra 1 (continuação).

\begin{tabular}{ccccc}
\hline $\begin{array}{c}\text { Tempo } \\
\text { Observado } \\
\text { (em dias) }\end{array}$ & $\begin{array}{c}\text { Indicador } \\
\text { de } \\
\text { Censura }\end{array}$ & $\begin{array}{c}\text { Estimativa da } \\
\text { Probabilidade } \\
\text { de }\end{array}$ & $\begin{array}{c}\text { Estimativa } \\
\text { dp }\end{array}$ & $\begin{array}{c}\text { Estimativa } \\
\text { Probab. } \\
\text { Falha }\end{array}$ \\
\hline 54,7 & 1 & 0,418454 & 0,066080 & 0,581548 \\
61,0 & 1 & 0,399433 & 0,065757 & 0,600587 \\
62,1 & 1 & 0,380413 & 0,065319 & 0,619587 \\
62,9 & 1 & 0,361392 & 0,064763 & 0,638608 \\
65,7 & 1 & 0,342371 & 0,064087 & 0,657629 \\
66,7 & 1 & 0,323351 & 0,063286 & 0,676549 \\
74,7 & 0 & 0,323351 & 0,063286 & 0,876549 \\
77,4 & 1 & 0,303141 & 0,062474 & 0,696859 \\
78,0 & 1 & 0,282932 & 0,061491 & 0,717068 \\
86,6 & 1 & 0,262722 & 0,060329 & 0,737278 \\
92,0 & 0 & 0,262722 & 0,060329 & 0,737278 \\
109,5 & 1 & 0,240829 & 0,059141 & 0,759171 \\
112,4 & 1 & 0,218935 & 0,057674 & 0,781065 \\
112,9 & 1 & 0,197042 & 0,055908 & 0,802958 \\
113,2 & 0 & 0,197042 & 0,055908 & 0,802958 \\
124,2 & 1 & 0,172412 & 0,054074 & 0,827588 \\
127,9 & 1 & 0,147781 & 0,051655 & 0,852219 \\
133,5 & 0 & 0,147781 & 0,051655 & 0,852219 \\
138,5 & 1 & 0,118225 & 0,049056 & 0,881775 \\
151,4 & 1 & 0,088689 & 0,044820 & 0,911331 \\
169,1 & 1 & 0,059113 & 0,038408 & 0,840887 \\
208,6 & 1 & 0,029556 & 0,028383 & 0,970444 \\
255,7 & 0 & 0,029556 & 0,028383 & 0,970444 \\
\hline
\end{tabular}

'desvio padrão da probabilidade de sobrevivência. 
Tabela 4 - Estimativas da probabilidade de sobrevivência, do desvio padrão da probabilidade de sobrevi vência e da probabilidade de falha de cada indivíduo da amostra 2 .

\begin{tabular}{|c|c|c|c|c|}
\hline $\begin{array}{l}\text { Tempo } \\
\text { observado } \\
\text { Cem dias? }\end{array}$ & $\begin{array}{c}\text { Indicador } \\
\text { de } \\
\text { Censura }\end{array}$ & $\begin{array}{c}\text { Esti mati va da } \\
\text { Probabili dade } \\
\text { de } \\
\text { Sobrevi vência }\end{array}$ & $\begin{array}{c}\text { Estimativa } \\
\text { dp } \\
\text { Prob. }\end{array}$ & $\begin{array}{c}\text { Estimativa } \\
\text { Probab. } \\
\text { Falha }\end{array}$ \\
\hline 0,2 & 1 & 0,983333 & 0,016527 & 0,016667 \\
\hline 0,3 & 0 & 0,983333 & 0,016527 & 0,016667 \\
\hline 0,6 & 1 & 0,966379 & 0,023373 & 0,033621 \\
\hline 0,7 & 1 & 0,949425 & 0,028455 & 0,050575 \\
\hline 0,9 & 1 & 0,932471 & 0,032609 & 0,067529 \\
\hline 1,0 & 0 & 0,932471 & 0,032009 & 0,067529 \\
\hline 1,6 & 1 & 0,915203 & 0,036290 & 0,084797 \\
\hline 1,9 & 1 & 0,897935 & 0,039501 & 0,102065 \\
\hline 3,7 & 1 & 0,880667 & 0,042348 & 0,119333 \\
\hline 3,8 & 1 & 0,863399 & 0,044900 & 0,136601 \\
\hline 4,0 & 1 & 0,846131 & 0,047206 & 0,153889 \\
\hline 4,0 & 1 & 0,828863 & 0,049300 & 0,171137 \\
\hline 4,4 & 1 & 0,811595 & 0,051208 & 0,188405 \\
\hline 5,9 & 1 & 0,794327 & 0,052950 & 0,205673 \\
\hline 6,2 & 1 & 0.777059 & 0.054542 & 0,222941 \\
\hline 7,8 & 1 & 0.759791 & 0,055997 & 0,240200 \\
\hline 8,0 & 1 & 0,742523 & 0,057325 & 0,257477 \\
\hline 10,0 & 1 & 0,725255 & 0,058535 & 0,274745 \\
\hline 10,4 & 1 & 0,707987 & 0,059634 & 0,292013 \\
\hline 11,2 & 1 & 0,690719 & 0,060628 & 0,309281 \\
\hline 11.5 & 1 & 0,673451 & 0,061522 & 0,326549 \\
\hline 11,9 & 1 & 0,656183 & 0,082321 & 0,343817 \\
\hline 13,4 & 1 & 0,638915 & 0,063028 & 0,361085 \\
\hline 14,2 & 1 & 0,621648 & $0,063646=$ & 0,378352 \\
\hline 14,5 & 1 & 0,604380 & 0,064178 & 0,395620 \\
\hline 14.7 & 1 & 0,587112 & 0,064625 & 0,412888 \\
\hline 14,8 & 1 & 0,569844 & 0,064991 & 0,430156 \\
\hline 16,4 & 1 & 0,552576 & 0,065275 & 0,447424 \\
\hline 17,1 & 1 & 0.535308 & 0,065479 & 0.464692 \\
\hline 17,5 & 1 & 0,518040 & 0,005805 & 0,481960 \\
\hline 17,8 & 1 & 0,500772 & 0,065651 & 0,499228 \\
\hline 17,9 & 0 & 0,500772 & 0,065651 & 0,499228 \\
\hline 18,2 & 1 & 0,482887 & 0,065097 & 0,517113 \\
\hline 18,5 & 1 & 0,465002 & 0,065653 & 0,534998 \\
\hline 19,2 & 1 & 0,447118 & 0,065519 & 0,552882 \\
\hline
\end{tabular}


Tabela 4 - Estimativas da probabilidade de sobrevi vência, do desvio padrão da probabilidade de sobrevi vência e da probabilidade de falha de cada individuo da amostra 2 (continuação) .

\begin{tabular}{|c|c|c|c|c|}
\hline $\begin{array}{l}\text { Tempo } \\
\text { Observado } \\
\text { (em dias? }\end{array}$ & $\begin{array}{c}\text { Indicador } \\
\text { de } \\
\text { Censura }\end{array}$ & $\begin{array}{c}\text { Estimati va da } \\
\text { Probabilidade } \\
\text { de } \\
\text { Sobrevi vência }\end{array}$ & $\begin{array}{c}\text { Estimativa } \\
d p^{2} \\
\text { Prob. }\end{array}$ & $\begin{array}{l}\text { Estimativa } \\
\text { Probab. } \\
\text { Falha }\end{array}$ \\
\hline 19,6 & 1 & 0,429233 & 0,055294 & 0.570767 \\
\hline 20,6 & 1 & 0,411348 & 0,064978 & 0,588652 \\
\hline 21.8 & 1 & 0,393463 & 0,064566 & 0,606537 \\
\hline 22,2 & 1 & 0,375579 & 0,064060 & 0,624421 \\
\hline 22,6 & 1 & 0,357694 & 0,063457 & 0,642306 \\
\hline 22,8 & 0 & 0,357694 & 0,063457 & 0,642300 \\
\hline 23,8 & 0 & 0,357694 & 0,063457 & 0,642300 \\
\hline 25,4 & 1 & 0,337822 & 0,082966 & 0,682178 \\
\hline 25,6 & 1 & 0,317950 & 0,062319 & 0.682050 \\
\hline 25,6 & 0 & 0,317950 & 0,062319 & 0,682050 \\
\hline 27,7 & 1 & 0,296754 & 0,061664 & 0,703240 \\
\hline 27,8 & 1 & 0,275557 & 0,060794 & 0.724443 \\
\hline 28,0 & 1 & 0,254360 & 0,059898 & 0,745640 \\
\hline 28,1 & 1 & 0,233163 & 0,058365 & 0,766837 \\
\hline 34,7 & 1 & 0,211967 & 0,056778 & 0,788033 \\
\hline 34,8 & 1 & 0,190770 & 0,054915 & 0,809230 \\
\hline 37,1 & 0 & 0,190770 & 0,054915 & 0,809230 \\
\hline 41,0 & 1 & 0,1 s6924 & 0,052975 & 0,833076 \\
\hline 46,5 & 0 & 0,1 B6924 & 0,052975 & 0,833070 \\
\hline 47,6 & 1 & 0,139103 & 0,050930 & 0,800897 \\
\hline 51,2 & 1 & 0,111283 & 0,047742 & 0,888717 \\
\hline 63,1 & 1 & 0,083462 & 0,043158 & 0,916538 \\
\hline 63,5 & 0 & 0,083462 & 0,043158 & 0,916538 \\
\hline 84.1 & 0 & 0,083462 & 0,043158 & 0,916538 \\
\hline 93,7 & 1 & 0 & 0 & 1 \\
\hline
\end{tabular}

'desvio padrão da probabili dade de sobrevi vência. 
Observando-se as Tabelas 3 e 4 percebe-se que em ambas amostras as probabilidades de sobrevivencia diminuem $e$ as de falhas aumentam com o tempo. Na amostra 1 , como a última observação é censura, tem-se que a probabilidade de sobrevivência não atinge o valor zero e, consequientemente, $a$ de falha não atinge 0 valor 1 , ao contrário do que ocorre com a amostra 2 . Podem-se notar estes fatos nas figuras $1=2$

Tabela 5 - Estimativa do tempo médio de vida e sua variância para cada uma das amostras.

\begin{tabular}{ccc}
\hline Amostras & Tempo médio de vida & Variância \\
\hline 1 & 64,744902 & 75,320298 \\
2 & 25,364913 & 12,391853 \\
\hline
\end{tabular}

- tempo médio de vida da amostra 2 foi calculado usando-se a fórmula $(2,24)$, pois a maior observação é tempo de morte. Mas na amostra 1 o tempo médio de vida foi calculado usando-se a fórmul a (2. 24), I i mitada a um tempo $L=208,6$ pols nesta amostra a maior observação é tempo de censura. 
76.

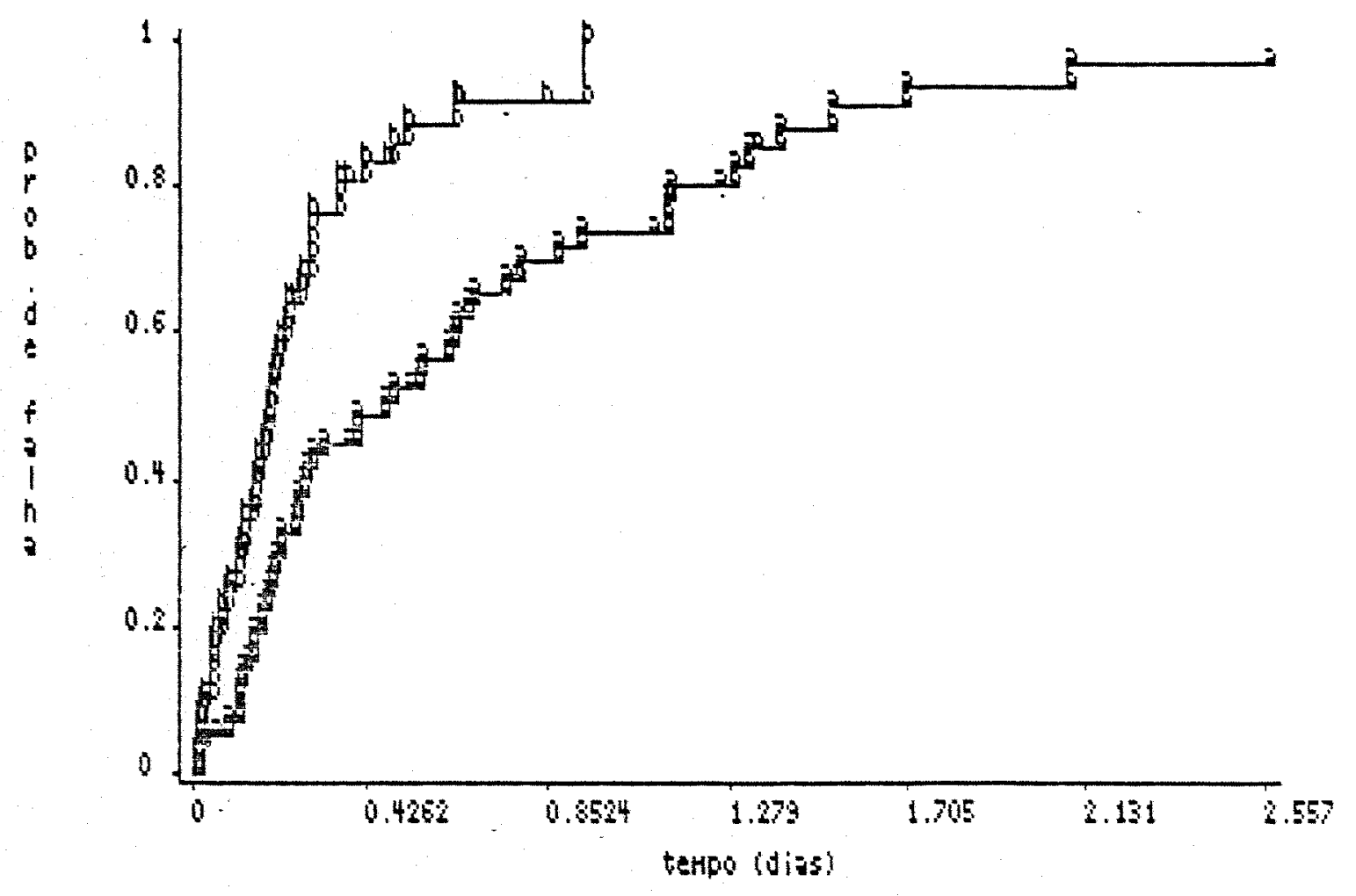

Figura 1 - Gráfico de tempo versus $\hat{S}_{k m}(t)$. Probabilidade de sobrevi vência.
a: amostra 1
b: amostra 2 


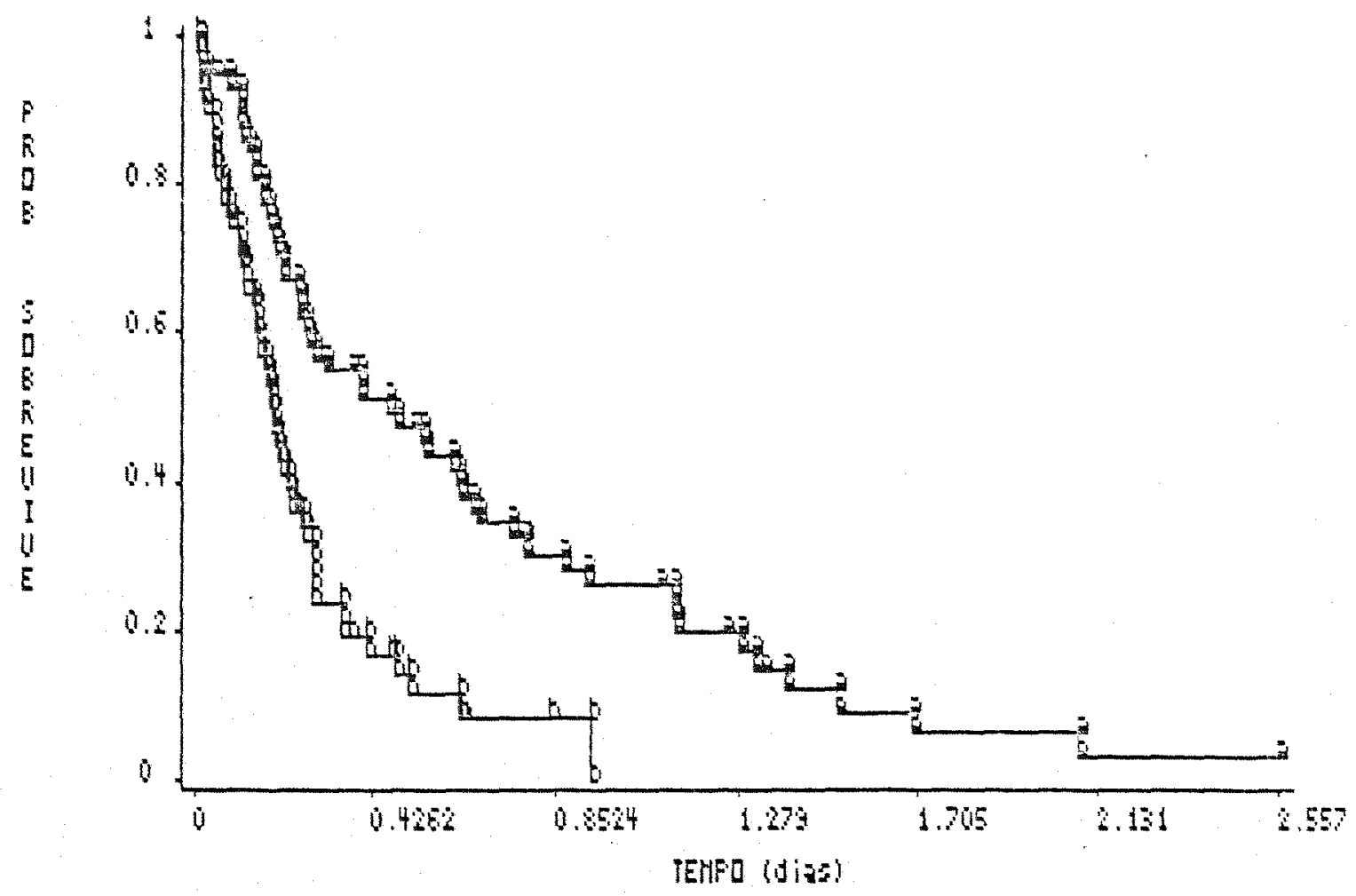

Figura 2 - Gráfico de tempo versus $F[t]$. Probabilidade de falha.

a: amostra 1

b: amostra 2 
O gráfico da figura 2 é o inverso do gráfico da figura 1, pois as probabilidades de falha e de sobrevi vência são complementares.

Quando se observa o gráfico de tempo versus $\hat{S}_{k m}(t)$, nota-se que o gráfico da amostra 2 cgrupo 2 atinge - valor zero mais rapidamente que o gráfico da amostra 1, ou seja, as probabilidades de sobrevi vência da amostra 2 tendem a zero mais rapidamente que as da amostra 1 . Se cada amostra fosse um tratamento, o individuo que recebeu o tratamento 2 teria em média uma probabilidade de falhar maior do que o individuo que recebeu o tratamento 1 , isto é, o tratamento 1 seria mais eficiente do que o tratamento 2.

Para confirmar esta diferenca entre as amostras foi feito o teste de "Logrank".

\subsection{Teste de "Logrank"}

Os resultados destes testes encontram-se nas

Tabel as $6=7$. 
79.

Tabela 6 - Escores calculados para as duas amostras combinadas e ordenadas.

\begin{tabular}{llll}
\hline Escores & Escores & Escores & Escores \\
\hline$-0,991667$ & $-0,738562$ & $-0,359580$ & 1,174191 \\
0,008333 & $-0,727326$ & $-0,342630$ & 0,208674 \\
$-0,983192$ & $-0,715962$ & 0,657370 & 0,244388 \\
$-0,974645$ & $-0,704468$ & 0,657370 & 0,281425 \\
$-0,968024$ & $-0,692840$ & $-0,324773$ & 0,319887 \\
$-0,957329$ & $-0,681075$ & $-0,306592$ & 0,359887 \\
$-0,948557$ & $-0,669171$ & $-0,288073$ & 0,401553 \\
0,051443 & $-0,657122$ & $-0,269205$ & 1,401553 \\
$-0,939628$ & $-0,644927$ & $-0,249974$ & 0,447008 \\
0,060372 & $-0,632582$ & 0,750026 & 0,494627 \\
$-0,930537$ & $-0,620082$ & $-0,229974$ & 0,544627 \\
$-0,921363$ & $-0,607423$ & $-0,209586$ & 1,544627 \\
$-0,912104$ & $-0,594603$ & $-0,188733$ & 0,600183 \\
$-0,902758$ & $-0,581616$ & $-0,167456$ & 1,600183 \\
$-0,893324$ & $-0,568458$ & $-0,145717$ & 0,662683 \\
$-0,883800$ & $-0,555125$ & $-0,123495$ & 0,729349 \\
$-0,874185$ & $-0,541611$ & $-0,100768$ & 0,800778 \\
0,125815 & $-0,527913$ & $-0,077512$ & 1,800778 \\
$-0,864381$ & 0,472087 & $-0,053702$ & 0,884111 \\
$-0,854480$ & $-0,513828$ & $-0,029312$ & 0,975020 \\
$-0,844480$ & $-0,499542$ & 0,970688 & 1,075020 \\
$-0,834379$ & $-0,485050$ & 0,970688 & 2,075020 \\
$-0,824175$ & $-0,470344$ & $-0,002996$ & 1,200020 \\
$-0,813866$ & $-0,455418$ & 0,024031 & 1,342877 \\
$-0,803449$ & $-0,440267$ & 0,051809 & 2,342877 \\
$-0,792923$ & 0,559733 & 0,080380 & 1,542877 \\
$-0,782284$ & $-0,424642$ & 1,080380 & 1,792877 \\
$-0,771532$ & $-0,408789$ & 0,110683 & 2,126211 \\
$-0,760682$ & $-0,392640$ & 0,141933 & 2,626211 \\
$-0,749673$ & $-0,376246$ & 0,174191 & 3,626211 \\
\hline
\end{tabular}


Tabela 7 - Estatística calculada para o teste "Logrank"

\begin{tabular}{ll}
\hline Estatistica & p-Valor \\
\hline 17,424075 & 0,000165 \\
\hline
\end{tabular}

Observando-se a estatistica deste teste e o seu p-valor, rejeita-se $H_{0}: S(t)_{1}=S(t){ }_{2}$, ou seja, as funcões de sobrevi vência diferem entre si a um nível de significância de 0,0001 . Portanto, o teste de "Logrank" confirma o que fai observado nos gráficos de $\hat{S}_{k m}(t)$ versus tempo.

\section{3. Métodos paramétricos}

De acordo com o programa de análise de sobrevi vência desenvol vido, primeiro obteve-se a cálculo das estimativas dos parâmetros gama e beta pelo método de Newton Raphson para a distribuicão valor extremo, em cada amostra, conforme as tabelas 8 e 9 .

Tabela 8 - Convergência obtida na amostra 1.

\begin{tabular}{cccc}
\hline Iteraçáo & log da verossimilhanca & Lambda 1 & Beta 1 \\
\hline 0 & $-90,832299$ & 4,03771 & 1,097536 \\
1 & $-90,685121$ & 3,83543 & 1,030775 \\
2 & $-90,681190$ & 3,83552 & 1,030997 \\
\hline
\end{tabular}


Tabela 9 - Convergência obtida na amostra 2.

\begin{tabular}{cccc}
\hline Iteracão & log da verossimilhança & Lambda 2 & Beta 2 \\
\hline 0 & $-90,735176$ & 3,249722 & 1,108600 \\
1 & $-90,386536$ & 3,227334 & 1,000867 \\
2 & $-90,341887$ & 3,228246 & 1,003242 \\
\hline
\end{tabular}

Após serem estimados os parâmetros da distribuicão valor extremo, foram feitos dois testes sob os paràmetros de cada amostra, conforme as tabelas $10,11,12$ e 13.

Tabela 10 - Resultado do teste $H_{0}: \lambda_{1}=0$ na amostra 1.

\begin{tabular}{lc}
\hline Estatistica & P-Valor \\
\hline 80,0158673 & 0 \\
\hline
\end{tabular}

Tabela 11 - Resultado do teste $H_{0}: \lambda_{2}=0$ na amostra 2.

\begin{tabular}{cc}
\hline Estatistica & P-Valor \\
\hline 103,151853 & 0 \\
\hline
\end{tabular}

Tabela 12 - Resultado do teste $H_{0}: \beta_{1}=1$ na amostra 1.

\begin{tabular}{cl}
\hline Estatistica & p-valor \\
\hline 0,079869 & 0,777747 \\
\hline
\end{tabular}


82.

Tabela 13 - Resultado do teste $H_{0}: \beta_{2}=1$ na amostra 2.

\begin{tabular}{cl}
\hline Estatistica & p-Valor \\
\hline 0,002158 & 0,962944 \\
\hline
\end{tabular}

Com os resultados das tabelas 10 e 11 vê-se que os paràmetros $\lambda_{1} \odot \lambda_{2}$ diferem de zero, ou seja, as hipóteses $H_{0}: \lambda_{1}=0$ e $H_{0}: \lambda_{2}=0$ são rejeitadas. Já com as resultados das tabelas $12=13$ vê-se que os parâmetros $\beta_{1} e$ $\beta_{2}$ não diferem de um, ou seja, não se rejeitam as hipóteses $H_{0}: \beta_{1}=1$ e $H_{0}: \beta_{2}=1$. Portanto, com estes resultados tem-se que o modelo que melhor se ajusta a cada uma das amostras é o exponencial, o que já era esperado, pois as amostras foram simuladas a partir de uma distribuicão exponencial.

Ajustando-se cada amostra ao modelo exponencial obteve-se a estimativa dos parâmetros $\lambda_{1}=\lambda_{2}$, os quais estão na Tabela 14.

Tabela 14 - Valores das estimativas de $\lambda_{1}$ e $\lambda_{2}$ com as respecti vas variâncias.

\begin{tabular}{ccr}
\hline Amostra & Estimativa & Variãncia \\
\hline 1 & 0,0145725 & 235,45169 \\
2 & 0,0395674 & 31,93698 \\
\hline
\end{tabular}


Para se confirmar os resultados obtidos com os testes da razão de verossimilhanca sob os parãmetros, foi utilizado o processo gráfico para identificacão dos modelos, ilustrados nas figuras 3 e 4 .

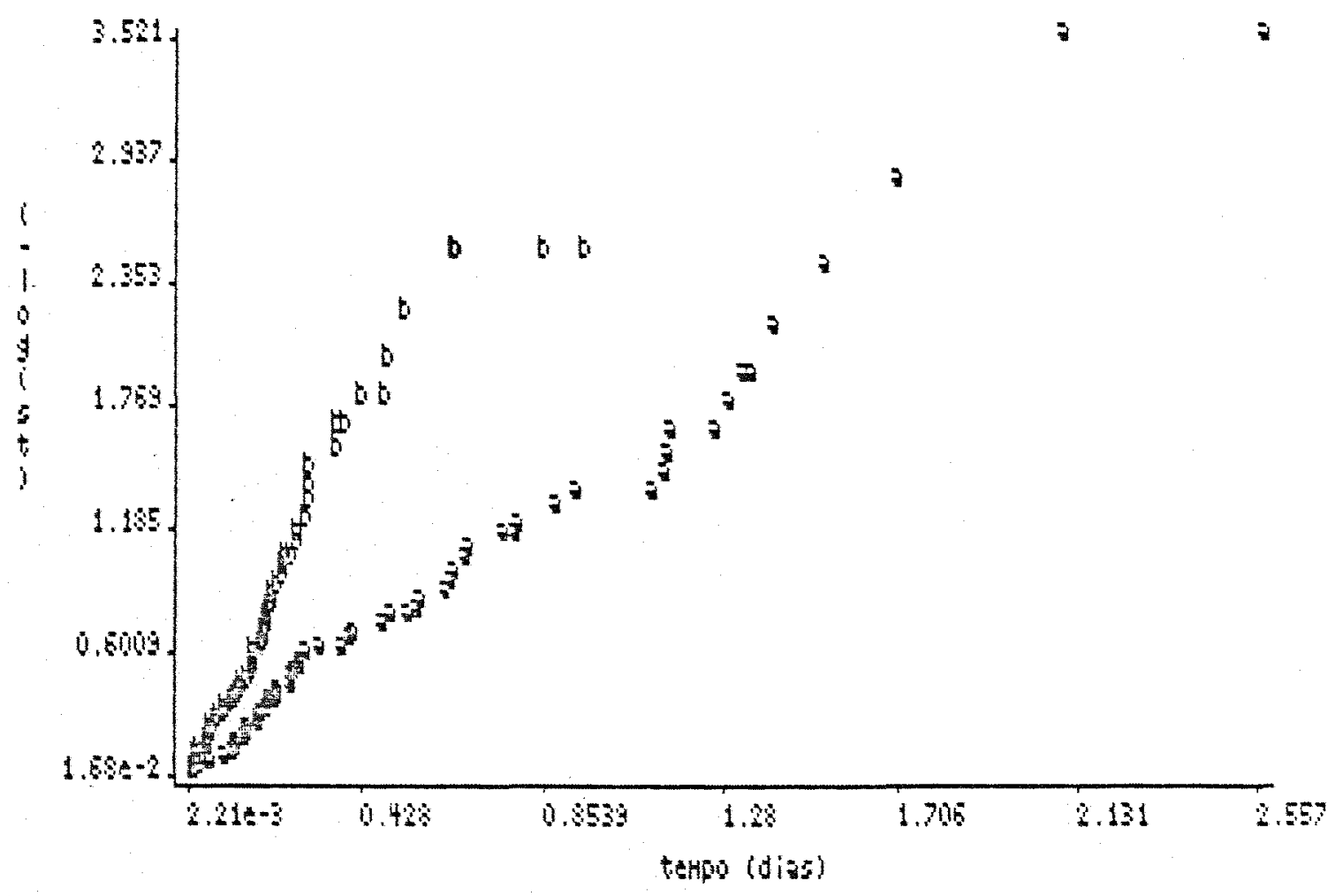

Figura 3 - Gráfico de tempo versus $-\log \left[\hat{s}_{k m}(t)\right]$

a: amostra 1

b: amostra 2 
84.

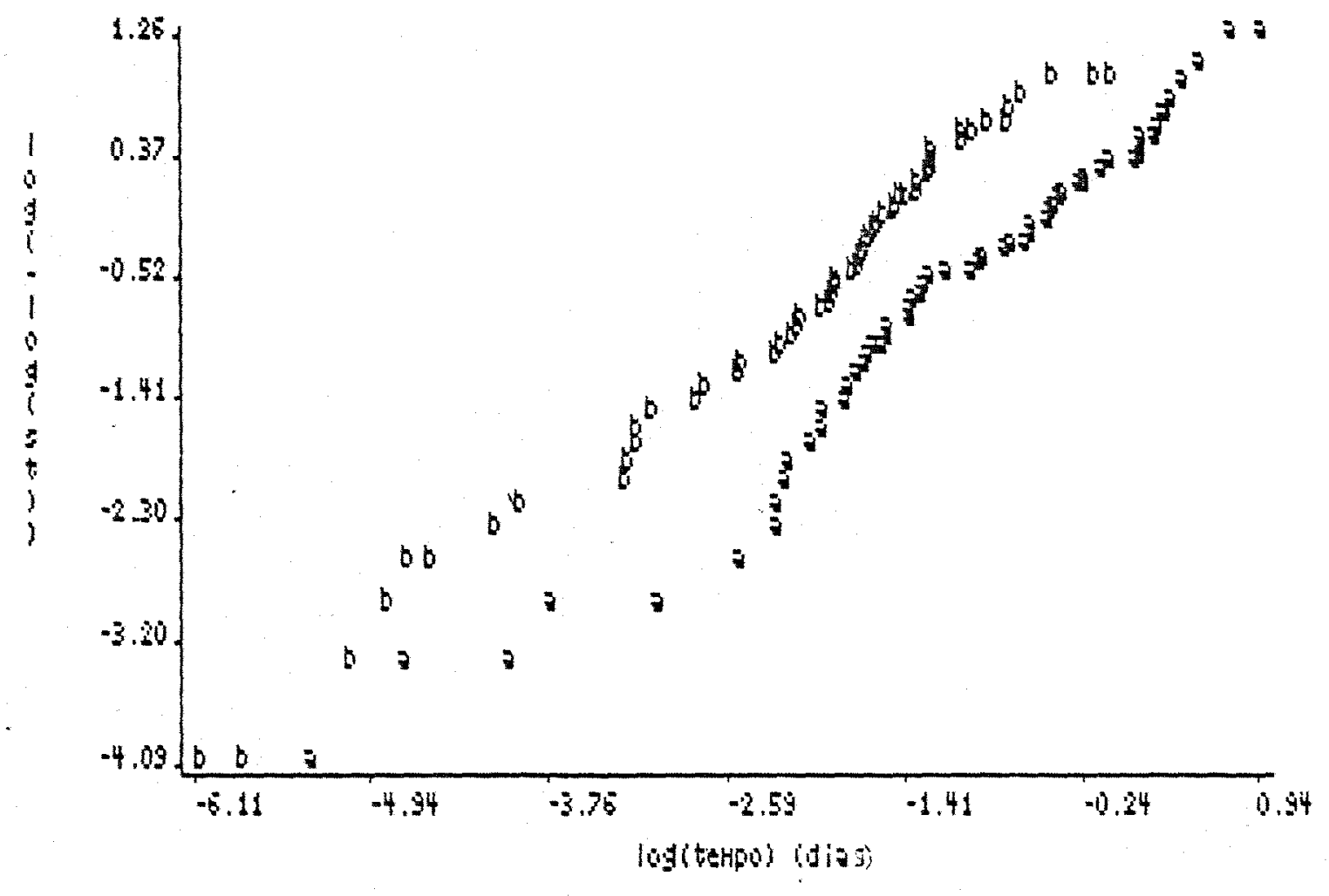

Figura 4 - Gráfico de $\log \left[\right.$ tempo versus $\log \left\{-\log \left[S_{k m}(t)\right]\right\}$ a: amostra 1

b: amostra 2 
Observando-se os gráficos pode-se dizer que na Figura 3 uma reta é mais visível que na figura 4. Mas é perceptivel que esta concl usão não está muito clara, pois é dificil verificar-se esta aproximacão visualmente. Pode-se sugerir que se faca uma regressão linear para se saber se a reta existe.

$$
\text { Visando-se confirmar a diferenca entre as }
$$

funcões de sobrevi vência, obtida pelo teste não paramétrico, fez-se um teste paramétrico.

\section{4. Teste de razáo de verossimil hança para duas amostras}

$$
\text { Aqui se quer observar se as duas }
$$

distribuicóos diferem, ou seja, quer-se testar $H_{0}: \lambda_{1}=\lambda_{2}=\lambda$ vs $H_{1}: \lambda_{1} \neq \lambda_{2}$.

De acordo com os dados, as estimativas dos parâmetros encontrados for am:

$$
\begin{aligned}
& \hat{\lambda}_{1}=0,01457 \\
& \hat{\lambda}_{2}=0,03958 \\
& \hat{\lambda}^{2}=0,02130
\end{aligned}
$$

fornecendo $\Lambda=6,235 \times 10^{-6}$.

$$
\begin{gathered}
\text { Tomando-se }-2 \log \Lambda, \text { encontrou-se: } \\
-2 \log \Lambda=23,97
\end{gathered}
$$

que, comparado com o valor de $x_{1,5 \%}^{2}=3,84$ e $x_{1,1 \%}^{2}=6,63$, rejeita-se $H_{0}$, isto é, as distribuicôes realmente diferem significativamente a nível de $1 \%$ 
86.

Para se compararem os métodos não paramétricos em relacăo aos paramétricos usou-se eficiência assintótica relativa.

4.5. Eficiencia assintótica relativa

De acordo com os dados e o que foi visto em (3.6) calculou-se a eficiencia assintótica relativa em cada tempo para cada amostra, e os resultados estão nas tabo as $16=17$. 
Tabela 16 - Tempo observado e eficiência assintótica relativa da amostra 1.

\begin{tabular}{|c|c|}
\hline Tempo (em dias) & Eficiência \\
\hline 0,5 & 0.01370 \\
\hline 0,8 & 0,02535 \\
\hline 1,7 & 0,05008 \\
\hline 2,3 & 0,05609 \\
\hline 4,5 & 0,12763 \\
\hline 7,7 & 0,20596 \\
\hline 9,9 & 0,25816 \\
\hline 10,0 & 0,25781 \\
\hline 10,4 & 0,26867 \\
\hline 10,7 & 0,27188 \\
\hline 12,6 & 0,31032 \\
\hline 13,3 & 0,32564 \\
\hline 13,4 & 0,32736 \\
\hline 15,8 & 0,36991 \\
\hline 15,8 & 0,37063 \\
\hline 16,8 & 0,38716 \\
\hline 17,7 & 0,40315 \\
\hline 18,3 & 0,41259 \\
\hline 18,9 & 0,42213 \\
\hline 19,9 & 0,43642 \\
\hline 20,6 & 0,44705 \\
\hline 20,7 & 0,44772 \\
\hline 24,1 & 0,49283 \\
\hline 24,2 & 0,49438 \\
\hline 24,7 & 0,50024 \\
\hline 26,0 & 0,31542 \\
\hline 26,4 & 0,51907 \\
\hline 27,8 & 0,53373 \\
\hline 30,9 & 0,56296 \\
\hline 31,3 & 0,80378 \\
\hline 36,7 & 0,61454 \\
\hline 38,7 & 0,61648 \\
\hline 39,1 & 0,63973 \\
\hline 45,8 & 0,64345 \\
\hline 47,7 & 0,64746 \\
\hline 54,1 & 0,64747 \\
\hline 54,1 & 0,64725 \\
\hline 54,7 & 0,63992 \\
\hline 61,0 & 0,63702 \\
\hline 62,1 & 0,63592 \\
\hline 62,9 & 0,62886 \\
\hline
\end{tabular}


88.

Tabela 16 - Tempo observado e eficiência assintótica relatiya da amostra 1 Continuacão).

\begin{tabular}{cc}
\hline Tempo (em dias) & Erílência \\
\hline 65,7 & 0,62588 \\
66,7 & 0,59771 \\
74,7 & 0,58643 \\
77,4 & 0,58354 \\
78,0 & 0,54257 \\
86,8 & 0,51475 \\
92,0 & 0,41968 \\
109,5 & 0,40403 \\
112,4 & 0,40152 \\
112,9 & 0,39968 \\
113,2 & 0,34255 \\
124,2 & 0,32457 \\
127,9 & 0,30816 \\
133,5 & 0,29793 \\
138,5 & 0,27487 \\
151,4 & 0,22227 \\
169,1 & 0,16218 \\
208,6 & 0,07507 \\
255,7 & 0,02743 \\
\hline
\end{tabular}


Tabela 17 - Tempo observado e eficiência assintótica relativa da amostra 2 .

\begin{tabular}{|c|c|c|}
\hline Tempo & Cem dias) & Eficiência \\
\hline & 0,2 & 0,01535 \\
\hline & 0,3 & 0,02037 \\
\hline & 0,6 & 0,04112 \\
\hline & 0,7 & 0,05200 \\
\hline & 0,9 & 0,05887 \\
\hline & 1,0 & 0,06875 \\
\hline & 1,6 & 0,10341 \\
\hline & 1,9 & 0,12289 \\
\hline & 3,7 & 0,228887 \\
\hline & 3,8 & 0,23108 \\
\hline & 4,0 & 0,24407 \\
\hline & 4,0 & 0,24485 \\
\hline & 4,4 & 0,26358 \\
\hline & 5,9 & 0,33401 \\
\hline & 6.2 & 0,34790 \\
\hline & 7,8 & 0,41029 \\
\hline & 8,0 & 0,41769 \\
\hline & 10,0 & 0,48403 \\
\hline & 10,4 & 0,49429 \\
\hline & 11,2 & 0,51714 \\
\hline & 11,5 & 0,52469 \\
\hline & 11,9 & 0,53349 \\
\hline & 13,4 & 0,56627 \\
\hline & 14,2 & 0,58109 \\
\hline & 14,5 & 0,58499 \\
\hline & 14,7 & 0,58890 \\
\hline & 14,8 & 0,59118 \\
\hline & 16,4 & 0,61283 \\
\hline & 17.1 & 0,62030 \\
\hline & 17,5 & 0,82422 \\
\hline & 17,8 & 0,62735 \\
\hline & 17,9 & 0,62775 \\
\hline & 18,2 & 0,63023 \\
\hline & 18,5 & 0,83254 \\
\hline & 19,2 & 0,63733 \\
\hline & 19,6 & 0,63973 \\
\hline & 20,6 & 0,64384 \\
\hline
\end{tabular}


90.

Tabela 17 - Tempo observado e eficiência assintótica relativa da amostra 2 (continuacão).

\begin{tabular}{cc}
\hline Tempo (em dias) & Eficiência \\
\hline 21,8 & 0,64690 \\
22,2 & 0,64735 \\
22,6 & 0,64760 \\
22,8 & 0,64761 \\
23,8 & 0,64684 \\
25,4 & 0,64261 \\
25,8 & 0,64209 \\
25,6 & 0,64205 \\
27,7 & 0,63168 \\
27,8 & 0,63082 \\
28,0 & 0,62985 \\
28,1 & 0,62940 \\
34,7 & 0,56994 \\
34,8 & 0,56860 \\
37,1 & 0,54258 \\
41,0 & 0,49435 \\
46,5 & 0,42567 \\
47,6 & 0,41126 \\
51,2 & 0,36701 \\
63,1 & 0,23834 \\
63,5 & 0,23493 \\
84,1 & 0,09628 \\
93,7 & 0,06099 \\
\hline
\end{tabular}


91.

Fazendo-se um gráfico de tempo versus eficiência para cada amostra (Figuras 5 e 6 ,

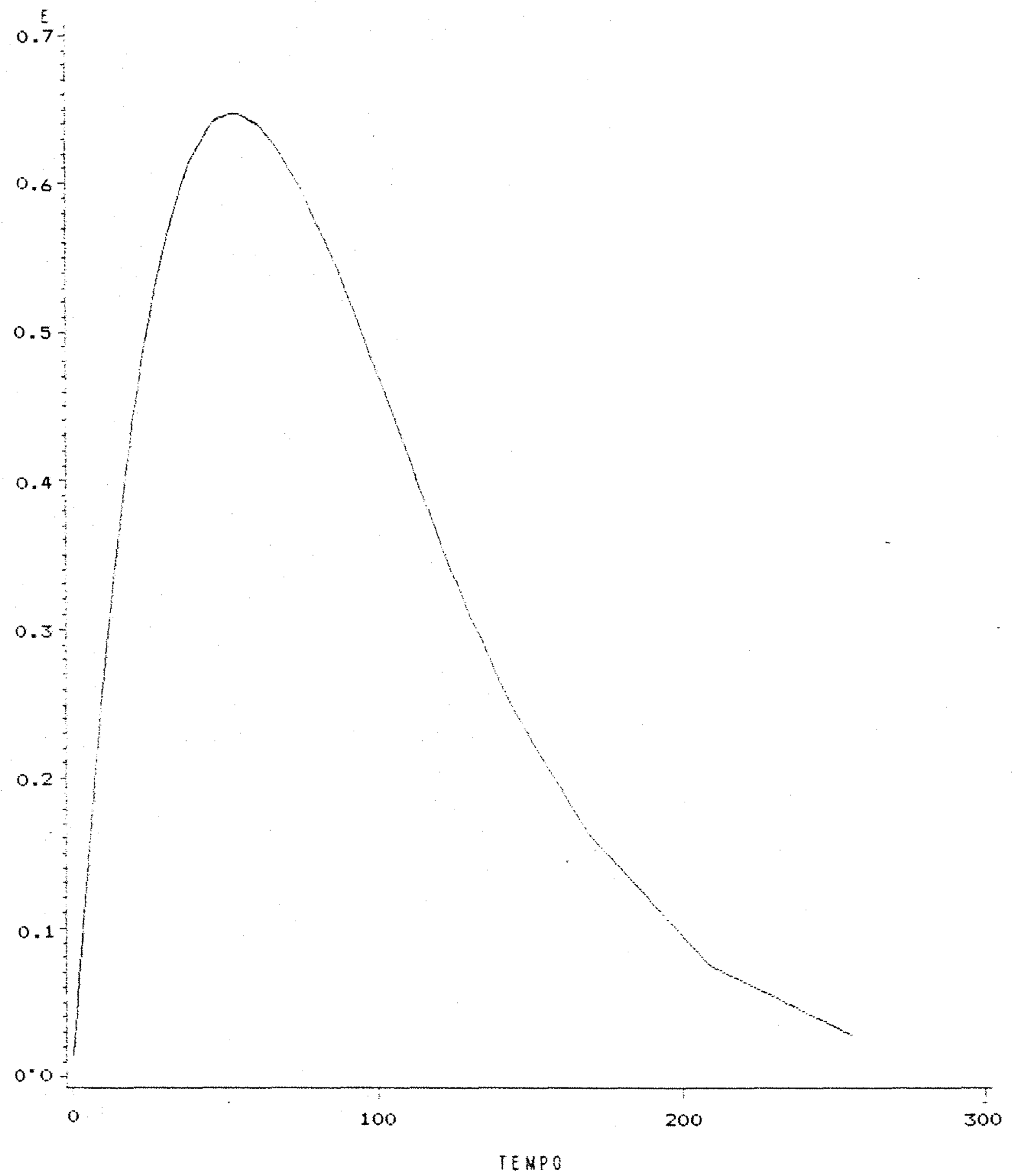

Figura 5 - Gráfico de eficiência assintótica relativa versus tempo da amostra 1. 
92.

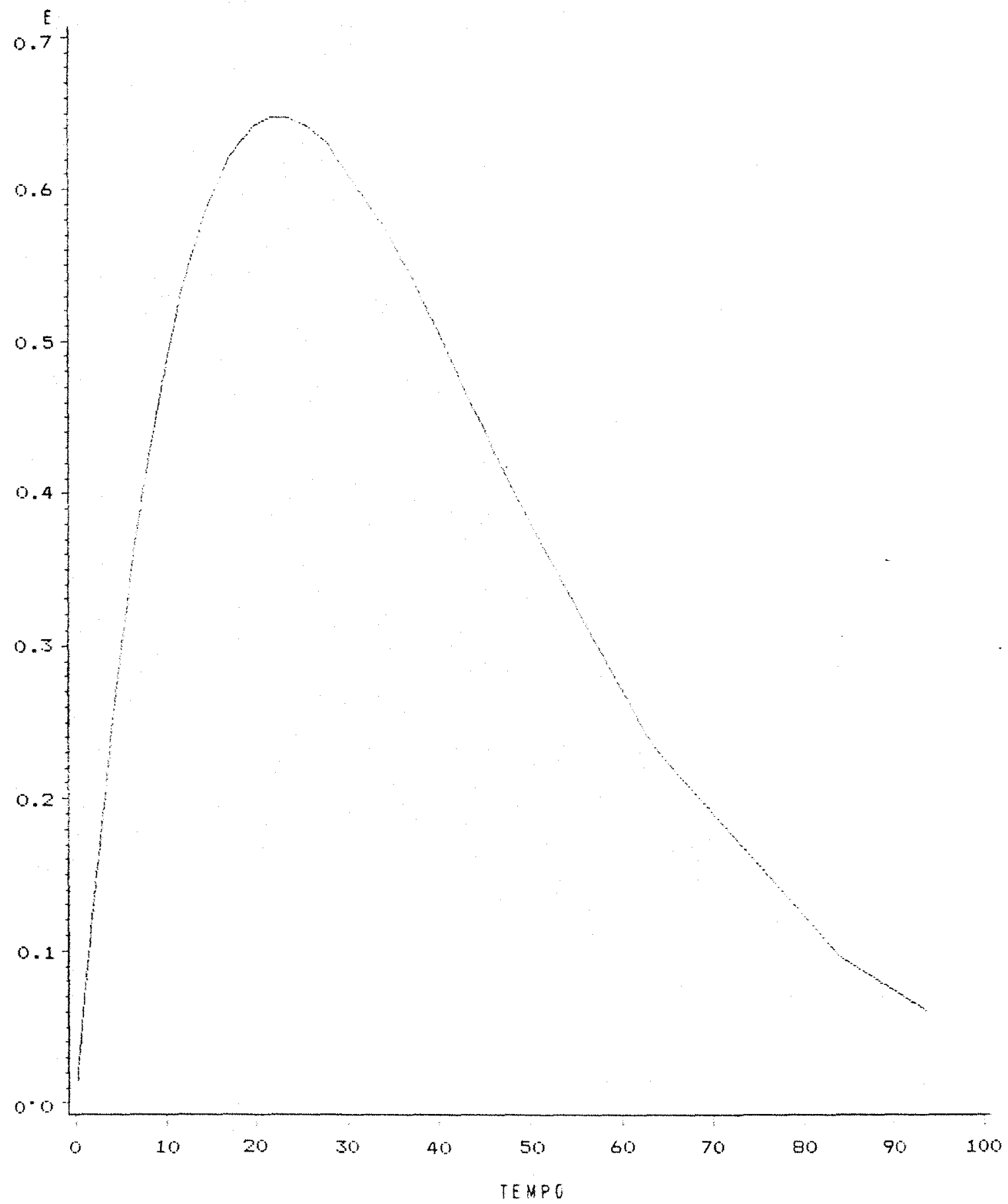

Figura 6 - Gráfico de eficiência assintótica relativa versus tempo da amostra 2 . 
93.

nota-se uma eficiência maior do método paramétrico em relacão ao não-paramétrico, pois para todo valor de $t$, $E_{A}(t)<1$, indicando uma menor variabilidade no modelo paramétrico, confirmando o que se encontrou na literatura.

Note-se, ainda, que a eficiência assintótica relativa é maior em torno do tempo médio. 


\section{REFERENNCIAS BIBLIOGRÁFICAS}

BERKSON, J. The Calculation of Survival Rates in Carcinoma and other malignant lesion of the Stomach. Philadelphia, W. B. Saunders Company, 1942. 120p.

BONFARINE, H.; RODRIGUES, J.; ACHCAR, J.A. Analise de Sobrevivencia. In: ESCOLA DE MODELOS DE REGRESGÃo, 2., Instituto de Matematica da Universidade Federal do Rio de Janeiro, 1991. $111 \mathrm{p}$.

EMBRAPA. SOC - Software cientifico: 3- ediçã. 1989. 325p. CoX, D.R. Some simple approximate tests for Poisson variates. Biometrika, 40:354-360, 1953.

GEHAN, E.A. A Generalized Wilcoxon test for comparing arbitrarily singly-censored samples. Biometrika, $52: 203-223,1965 a$.

GEHAN, E.A. A generalized two-sample wilcoxon test for doubly-censored data. Biometrika, 52:650-653, 19650.

IRWIN, j.0. The Standard Error of An Estimate of Expectational Life. Journal of Hygiene, 47: 188-9. 1949.

WNIAN, E.I. \& MEIER, P. Nonparametric estimation from incomplete observations. Journal of the American Statistical Association, 53:457-481, 1958. 
LAWLESS, J.F. Statistical models and methods for lifetime data. New York, Wiley, 1982. 341p.

LEE, E.T. Statistical methods for survival data analysis. Belmont, Lifetime Learning Publications, 1980. 557 p.

LEITE, J.G. \& SINGER, J.M. Metodos assintoticos em estatistica-fundamentos e aplicaçőes. In: SIMPósio NACIONAL DE PROBABILIDADE E ESTATISTICA, 9, Instituto de Matemática Estatistica da Universidade de São Paulo. Săo Paulo, 1990. 130p.

LIMA, A.C.P. Estimaçăo em modelos de sobrevivência. Săo Paulo, 1988. 110p. Mestrado - Instituto de Matemática e Estatistica/USP).

MANTEL, N. \& HAENSZEL, W. Statistical aspects of the analysis of data from retrospective studies of disease. Journal of the National Cancer Institute, 22:719-748, 1959.

MANTEL, N. Ranking Procedures for arbitrarily restricted observations. Biometrics, 23:65-78, 1967.

MILLER, R.G. Survival analysis. New York, Wiley, 1981 . $237 \mathrm{p}$.

MILLER, R.G. What price Kaplan-Meier?. Biometrics, $39: 1077-1091,1983$.

PETO, R. \& PETO, J. Asymptotically efficient rank invariant procedures. Journal of the Royal Statistical Society, $26(A): 258-261,1972$. 
96.

SAS INSTITUTE. SASASTAT guide for personal computers; version 6 edition. Cary, 1987, 1028p.

THOMAN, D.R. \& BAIN, L.J. Two sample tests in the weibull distribution. Technometrics, 11(4):805-815, 1969 . 